\title{
Post-weaning diarrhea in pigs weaned without medicinal zinc: risk factors, pathogen dynamics, and association to growth rate
}

\author{
Esben Østergaard Eriksen ${ }^{1 *} \mathbb{0}$, Egle Kudirkiene ${ }^{1}$, Anja Ejlersgård Christensen², Marianne Viuf Agerlin ${ }^{3}$, \\ Nicolai Rosager Weber ${ }^{3}$, Ane Nødtvedt ${ }^{4}$, Jens Peter Nielsen ${ }^{1}$, Katrine Top Hartmann ${ }^{1}$, Lotte Skade ${ }^{3}$, \\ Lars Erik Larsen ${ }^{1}$, Karen Pankoke ${ }^{1}$, John Elmerdahl Olsen ${ }^{1}$, Henrik Elvang Jensen ${ }^{1}$ and Ken Steen Pedersen ${ }^{1,2}$
}

\begin{abstract}
Background: Porcine post-weaning diarrhea (PWD) has reemerged as an important topic in pig production, as common control strategies based on prophylactic use of antimicrobials and zinc oxide have been deemed unsustainable. The objectives of this study were to estimate the cumulative incidence of porcine post-weaning diarrhea with different etiologies in production systems weaning without zinc oxide and prophylactic antimicrobials, to assess risk factors for post-weaning diarrhea, and to estimate the impact of post-weaning diarrhea on growth rate. A cohort study was conducted at two commercial indoor producers weaning without medicinal zinc oxide and prophylactic antimicrobials.

Results: Piglets were included at birth $(n=300)$ and 272 survived until weaning. After insertion to the nursery units, the piglets were clinically examined every day for 14 days, and rectal swabs were collected and analyzed for enterotoxigenic Escherichia coli (ETEC) and rotavirus A. The cumulative incidences of PWD the first 14 days after insertion to the nursery units were $41.8 \%(\mathrm{Cl} 33.6,50.4)$ and $51.1 \%(\mathrm{Cl} 42.3,60.0)$ at the two producers, respectively. We found a low incidence of cases associated to ETEC, and detected a substantial proportion of cases associated to rotavirus. We observed a biphasic pattern in the assumed etiology with rotavirus occurring first, and then a shift towards cases associated to ETEC/non-ETEC hemolytic E. coli. Being offspring of older sows was a protective factor for the development of PWD (Hazard ratio $=0.88[\mathrm{Cl} 0.78,0.99]$ per unit increase in parity of the dam). Low birth weight reduced the post-weaning growth rate $(-5.2 \mathrm{~g} /$ day $[\mathrm{Cl}-7.5,-2.9]$ per $100 \mathrm{~g}$ decrease in birthweight) and increased the hazard of developing PWD (Hazard ratio for birthweight below $1100 \mathrm{~g}: 2.30$ [Cl 1.41-3.74]). The combined effect of having diarrhea for 2 days or more and receiving antimicrobial treatment was associated with an increased average daily weight gain.
\end{abstract}

Conclusions: This study suggests novel insights regarding pathogen dynamics and risk factors for PWD in productions not using prophylactic antimicrobials and medicinal zinc. The findings may have important implications for both antimicrobial usage and prevention strategies.

Keywords: Post-weaning diarrhea, Weaning, Pig, Rotavirus, E. coli, Enterotoxigenic, Weight gain

*Correspondence: esbene@sund.ku.dk

1 Department of Veterinary and Animal Sciences, University of Copenhagen, Copenhagen, Denmark

Full list of author information is available at the end of the article

\section{Introduction}

Weaning of pigs is a delicate process where suckling is terminated and solid food replaces the milk-based diet. If humans do not intervene, piglets of the domesticated 
swine will gradually undergo this transition completing it when approximately $15-22$ weeks old [1]. In contrast, the weaning takes place as an abrupt event in the intensive indoor pig production. Under common Danish and European intensive production schemes, piglets are removed from the sow and weaned to special nursery units at 3-5 weeks of age. At this age the colostrogenic immunity is declining and the lactogenic immunity is lost from the discontinued suckling [2,3]. Furthermore, the piglets have an immature gut with a sub-optimal microbial community, an undeveloped mucosal-immunity and an impaired intestinal epithelial barrier function [4-7], and they are not adapted to solid feed. In addition, the gut health might be further compromised by the stressful events during weaning $[8,9]$, and the new environment where surface contamination and pen mates might introduce the piglets to new pathogens. This leaves the piglets in a very vulnerable position.

Post-weaning diarrhea (PWD) is a multifactorial condition occurring the first 14 days after weaning where the clinical sign diarrhea (i.e. defecation with increased rate, volume and water content) is resulting from the aforementioned factors commonly enhanced by an infection with specific pathogens. The most important pathogen in this regard is reported to be enterotoxigenic Escherichia coli (ETEC) [10]. However, PWD with no detection of ETEC is common [11], and it has been suggested that an intestinal dysbiosis in itself might cause intestinal inflammation and diarrhea after weaning in pigs [4]. Rotavirus is another commonly occurring [12] and contributing pathogen $[13,14]$. Porcine enteric coronaviruses are also important pathogens [15], but Denmark is declared free from these [16].

Traditionally, pig producers have succeeded with weaning at an early age with limited signs of gastrointestinal disease shortly after weaning. This has to a large extent been possible by the provision of oral antimicrobials [17] and high doses of in-feed medicinal zinc oxide [18-20]. However, the use of antimicrobials poses a risk to both human and animal health by selecting for antimicrobial resistance [21, 22]. Likewise, medicinal zinc oxide coselects for antimicrobial resistance, and the use possess an environmental hazard, as most of the zinc is excreted with the feces and through manuring it accumulates in soil [23]. Accordingly, medicinal zinc oxide has been prohibited in the European Union effectively coming into force no later than June 2022 [24]. Antimicrobial growth promoters have been banned in the European Union since 2006 [25] and lately other parts of the world [26], and prophylactic use of antimicrobials is also prohibited in many European countries including Denmark [27]. Therapeutic and metaphylatic use of antimicrobials remains an option [27]. However, there is a strong demand for reduction of the use by the public, the consumers, and the authorities globally [28-30]. Consequently, the pig industry must adopt novel strategies for the control of PWD.

The porcine intestinal disease complex occurring in older nursery pigs [31] sometimes have a low-pathogenic nature [32], in which case antimicrobial batch medications cannot be justified [32-34]. Analogously, pigs, which are not given medicinal zinc oxide, might experience PWD where antimicrobial batch medications cannot be justified. Previous studies (e.g. [11]) have indicated that ETEC is not necessarily present in all PWD outbreaks, and this should be further investigated. As a key for prevention, risk factors for PWD in such pigs should also be determined. Furthermore, impaired gut health can be associated with reduced productivity, which is undesirable from the perspective of resource use, climate gas emissions, and production economy [35-37].

Therefore, the present study investigated piglets raised at commercial Danish intensive indoor producers weaning without medicinal zinc and prophylactic antimicrobials. The objectives were to estimate the cumulative incidence of pigs which develop clinical signs of diarrhea associated with a bacterial intestinal infection during the first 14 days after insertion to the nursery unit, to assess early-life risk factors for post-weaning diarrhea, and to investigate the association between post-weaning diarrhea and growth rate.

\section{Results}

\section{Description of the study population}

This cohort study encompassed piglets from $30 \mathrm{~L}$ located in two commercial pig producers in Denmark during September and October 2019. The litters consisted of $90 \%$ live born piglets, the median litter size was 23 (range: 14-28), and the parity of the sows ranged from one to seven. Details of these parameters are summarized in Additional file 1: Additional table A. In Table 1, we have summarized descriptive parameters of the cohort followed at the two producers.

One piglet was missing at insertion to nursery unit $\mathrm{B}$, and therefore assumed dead in the suckling period. Apart from this, all 300 piglets were followed throughout the study period. As seen in Table 1, sex was distributed approximately evenly at birth at both producers. At insertion to the nursery unit, the males had been castrated.

Among all piglets $(n=300)$, three had missing registration of which sow/farrowing pen they were housed in at the time of death $(n=2)$ or weaning $(n=1)$. As seen in Table 1 , a majority $(n=187 / 297)$ was found at a foster sow instead of the dam.

Both producers practiced routine IM injections with antimicrobials during the first day of life to prevent 
Table 1 Summary of the piglets included in a cohort study of post-weaning diarrhea

\begin{tabular}{|c|c|c|}
\hline & Producer $\mathrm{A}$ & Producer B \\
\hline \multicolumn{3}{|l|}{ Sex at birth } \\
\hline Female & $64 / 150(43.7 \%)$ & $72 / 150(48.0 \%)$ \\
\hline Male & $86 / 150(57.3 \%)$ & $78 / 150(52.0 \%)$ \\
\hline \multicolumn{3}{|l|}{ Sex at insertion ${ }^{a}$} \\
\hline Female & $61 / 141(43.2 \%)$ & $63 / 131(48.1 \%)$ \\
\hline Male & $80 / 141(56.7 \%)$ & $68 / 131(51.9 \%)$ \\
\hline Pre-weaning mortality rate ${ }^{b}$ & $9 / 150(6.0 \%)$ & $19^{c} / 150(12.7 \%)$ \\
\hline Moved to foster sow & $113 / 149^{e}(75.8 \%)$ & $74 / 148^{f}(50 \%)$ \\
\hline Weaned in the farrowing unit ${ }^{d}$ & $61 / 140^{e}(43.6 \%)$ & $51 / 131(38.9 \%)$ \\
\hline \multirow[t]{3}{*}{ Mean birth weight (g) } & 1345 (SD: 316) & 1344 (SD: 302) \\
\hline & Range: 540-2080 & Range: 690-2070 \\
\hline & $n=150$ & $n=150$ \\
\hline \multirow[t]{3}{*}{ The mean body weights at insertion to the nursery units ( $\mathrm{g}$ ) } & 6054 (SD: 1670) & 6549 (SD: 1484) \\
\hline & Range: $2100-11,500$ & Range: $2900-11,000$ \\
\hline & $\mathrm{n}=140^{\mathrm{e}}$ & $n=131$ \\
\hline \multirow[t]{3}{*}{ Average daily weight gain the first 14 days after insertion to the nursery units ( $\mathrm{g}$ ) } & 155 (SD: 59 g) & 168 (SD: 55) \\
\hline & Range: $14-300$ & Range: $36-321$ \\
\hline & $\mathrm{n}=133$ & $\mathrm{n}=125^{\mathrm{e}}$ \\
\hline
\end{tabular}

${ }^{\text {a }}$ Sex at insertion was recoded to be in accordance with the sex registered at birth whenever these registrations did not agree $(\mathrm{n}=2)$

${ }^{b}$ Dead/euthanized by herd personnel

${ }^{c}$ Including one pig lost from follow up that was assumed to be dead

${ }^{d}$ Before the common weaning day

e Data from one piglet was missing

${ }^{f}$ Data from two piglets were missing

neonatal infections (Producer A: dihydrostreptomycin $31.25 \mathrm{mg}$ and benzylpenicillin procaine 25,000 UI per $1 \mathrm{~kg}$ bodyweight [Streptocillin ${ }^{\circledR}$ vet., Boehringer Ingelheim]. Producer B: Amoxicillin trihydrate $37.5 \mathrm{mg} / \mathrm{pig}$, [Clamoxyl $^{\circledR}$ Prolongatum Vet., Zoetis]). Apart from this, 24 piglets received an antimicrobial treatment before weaning at producer A; six of these were against diarrhea. Seven pigs were subjected to an antimicrobial treatment before weaning at producer B.

We aimed at not interfering with the producers' usual management practices. Hence, herd personnel made decision about weaning piglets if a sow were to be used as a foster sow. Consequently, a substantial proportion was weaned earlier than common weaning day at both producers (Table 1 ). The first piglets were weaned at study day 21 and 20 at producer A and B respectively, and the distribution of weaning age is displayed in Fig. 1 (note that weaning before 21 days of age is prohibited unless due to health or welfare issues, see ethical statement). The age at weaning was most commonly 26 days and 25 days at the two producers, respectively.

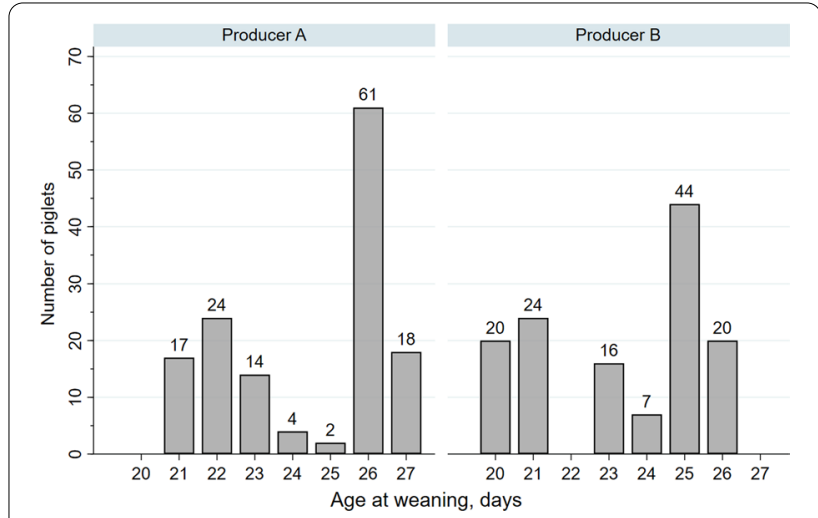

Fig. 1 Age at weaning in two cohorts of piglets followed at two Danish indoor producers

\section{Mortality rates and causes of death}

The pre-weaning mortality rates are presented in Table 2. The most common causes of death were non-infectious i.e. crushing by the sow $(n=10)$ and starvation $(n=4)$. Starvation was only recorded at producer B. Infectious causes of death included polyserositis $(n=1)$, enteritis, enterocolitis $(n=2)$, polyarthritis $(n=2)$ and 
Table 2 Toxin and fimbriae types of hemolytic E. coli from weaned Danish piglets

\begin{tabular}{|c|c|c|c|c|}
\hline \multirow[t]{2}{*}{ Genotype } & \multicolumn{2}{|l|}{ Producer A } & \multicolumn{2}{|l|}{ Producer B } \\
\hline & All isolates ${ }^{a}$ & $\begin{array}{l}\text { New (first or second) diarrhea } \\
\text { cases }\end{array}$ & All isolates ${ }^{a}$ & $\begin{array}{l}\text { New (first or } \\
\text { second) diarrhea } \\
\text { cases }\end{array}$ \\
\hline $\mathrm{F} 18+\mathrm{STa}+\mathrm{STb}$ & 144 & 21 & 4 & 1 \\
\hline $\mathrm{F} 18+\mathrm{STb}+\mathrm{LT}$ & 0 & & 16 & 7 \\
\hline $\mathrm{F} 4+\mathrm{STb}+\mathrm{LT}$ & 0 & & 3 & 2 \\
\hline F18 & 0 & & 118 & 24 \\
\hline $\mathrm{STa}+\mathrm{STb}$ & 0 & & 1 & 1 \\
\hline $\mathrm{STb}+\mathrm{LT}$ & 0 & & 1 & 1 \\
\hline $\mathrm{STb}$ & 4 & 1 & 5 & 2 \\
\hline No fimbria or toxins & 19 & 3 & 49 & 4 \\
\hline Total & 167 & & 193 & \\
\hline Missing values ${ }^{b}$ & 17 & 2 & 19 & 11 \\
\hline
\end{tabular}

Isolates were cultured from rectal swabs collected within the first 14 days after insertion to the nursery unit, and tested for F18 and F4, and STa, STb and LT

${ }^{\text {a } A l l}$ isolates including both systematically sampled pigs and samples from diarrhea cases

${ }^{\mathrm{b}} \mathrm{PCR}$ results from 34 samples, where hemolytic E. coli was deemed dominant were missing. Of these, 13 were from new cases of diarrhea

osteomyelitis $(n=1)$. In six of the pigs a cause of death could not be stated due to lack of pathological changes or because the autolytic changes made the pathological evaluation impossible. A complete table of causes of death and associated pathological manifestations is included in Additional file 1: Additional table 2. No pigs died after weaning, but for animal welfare reasons, four pigs in poor general condition were euthanized by the investigators during the 14 days the pigs were followed in the nursery (producer $\mathrm{A} n=3$, producer $\mathrm{B}=1$ ).

\section{Occurrence of diarrhea}

In nursery A, 59 piglets experienced at least one case of diarrhea, and 67 pigs did so in nursery B. The corresponding cumulative incidence of diarrhea during the first 14 days after insertion in the nursery was $41.8 \%$ (CI 33.6, $50.4)$ in nursery $A(n=141)$ and $51.1 \%(C I 42.3,60.0)$ in nursery $B(n=131)$. The incidence rate of first cases of diarrhea was 4.55 (CI 3.52, 5.87) diarrhea cases/100 piglet days in nursery A, and 5.06 (CI 3.98, 6.43) diarrhea cases/100 piglet days in nursery B. Kaplan-Meier failure estimates for first cases of diarrhea is presented for each producer in Fig. 2. At producer A, eight pigs experienced a second case of diarrhea, while 16 did so at producer B. The prevalence proportions of pigs suffering from diarrhea during the 14 days are displayed in Fig. 3.

\section{Microbiology}

Samples were collected in cases of diarrhea for all pigs in the cohort, and additionally half of the piglets were systematically sampled for bacteriology every second day. Bacterial isolation descriptions were missing for

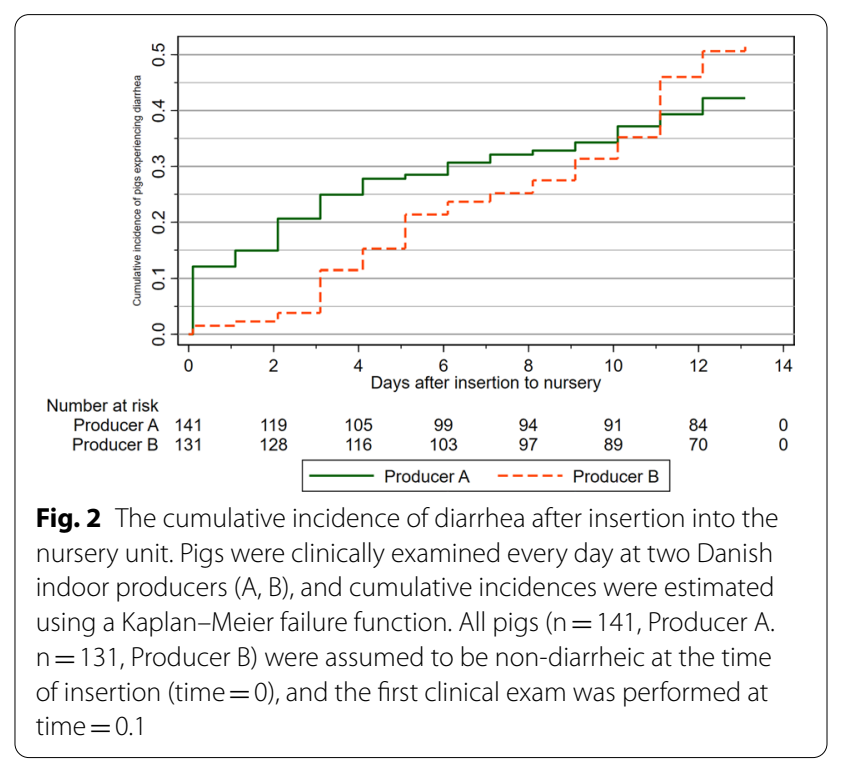

11 systematic sampling points in nursery A and two in nursery $\mathrm{B}$, and isolation descriptions were missing for two and five first cases of diarrhea samplings in nursery $A$ and $B$ respectively. PCR was used to determine toxin and fimbriae profiles of $E$. coli isolates. Results from the PCR lacked for 36 isolates that were hemolytic E. coli and which fulfilled the criteria for abundant growth. Of these missing values, 13 originated from first $(n=11)$ or second $(n=2)$ incidences of diarrhea, and 23 from the systematic sampling. Among the 360 hemolytic E. coli with available PCR results, $\mathrm{F} 18+\mathrm{STa}+\mathrm{STb}(\mathrm{n}=144)$ was the most common genotype in nursery $\mathrm{A}$, and F18 without 


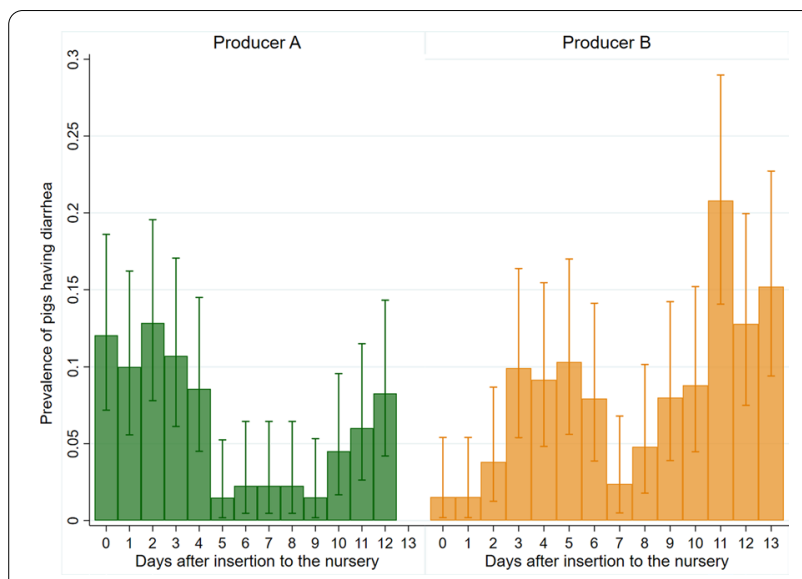

Fig. 3 Prevalence of diarrhea during the first 14 days after insertion in the nursery unit. Figure legend: Prevalence proportion with 95\% confidence intervals (Clopper-Pearson) of pigs having diarrhea during the first 14 days after insertion in the nursery unit in two Danish indoor productions $(\mathbf{A}, \mathbf{B}) \cdot n=131$ and $n=142$ at day 0 , and $n=133$ and $n=125$ at day 13 in the two nurseries $A$ and $B$, respectively. The prevalence was 0 at day 13 in nursery $\mathrm{A}$

the investegated toxins $(\mathrm{n}=118)$ was the most common genotype in nursery $\mathrm{B}$ (Table 2).

The systematic sampling offered a basis for mapping of $E$. coli shedding over time. Figure 4 presents the cumulative incidence of pigs shedding hemolytic E. coli to an extent where the defined quantitative criteria for "abundant growth" was fulfilled. It is seen that almost all pigs excreted $E$. coli above this level in at least one occasion during the first 13 days after insertion. Likewise, the shedding of ETEC was also mapped (Fig. 5). To

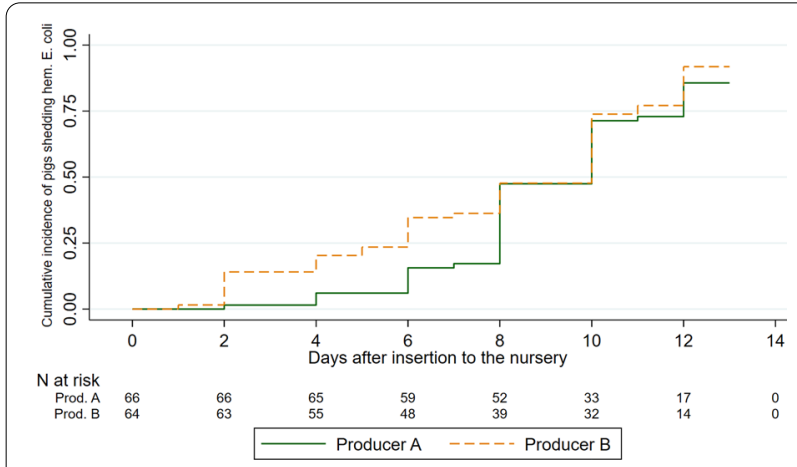

Fig. 4 The cumulative incidence of hemolytic E. coli shedding after insertion into the nursery unit. Figure legend: The cumulative incidence (Kaplan-Meier failure estimates) of fecal shedding of hemolytic $E$. coli as a function of time since insertion in the nursery unit (days) at two Danish indoor productions (A, B). The pigs were systematically sampled every second day. Failure was defined as: Rectal swabs cultured on blood agar displayed abundant growth of hemolytic E. coli-like colonies be considered a failure event in this regard, the defined quantitative criteria were still applied, and ETEC was defined as having at least one fimbria (F4 or F18) gene and at least one toxin (STa, STb or LT) gene. There was no substantial shedding of ETEC the first 6 days after insertion. Interestingly, the frequent shedding of hemolytic $E$. coli in nursery B (Fig. 4) did not reflect a frequent shedding of ETEC (Fig. 5 and Table 2).

The effect of the E. coli virulence factors was explored by comparing the incidence rates of diarrhea cases between pigs shedding $E$. coli strains with different profiles of hemolytic ability, fimbriae and toxins. A Poisson regression model was based on 33 cases occurring during 941 pig days with 455 bacteriological recordings, and the results are displayed in Table 3. Nine additional cases had missing values for the virulence profile of $E$. coli on the case-day, and these were omitted from the analysis. The modelling indicated that new cases of diarrhea occurred at a lower rate in pigs shedding hemolytic $E$. coli that were fimbria positive but lacked toxins, compared to pigs shedding enterotoxigenic $E$. coli carrying both fimbria and toxin genes $(\mathrm{IRR}=0.25$ [CI $0.09-0.68])$ (Table 3). Diarrhea occurred at a greater rate in pigs shedding hemolytic E. coli carrying fimbria but no toxins compared to pigs not shedding hemolytic $E$. coli.

\section{Diarrhea cases sorted on assumed etiology}

The diarrhea cases were sorted on assumed etiologies according to the definitions described in the Methods paragraph. For this purpose, imputations were made for 11 missing values of ETEC and four missing value for rotavirus A. Reasonable imputations could not be made for 10 pigs with missing values, and thus they received

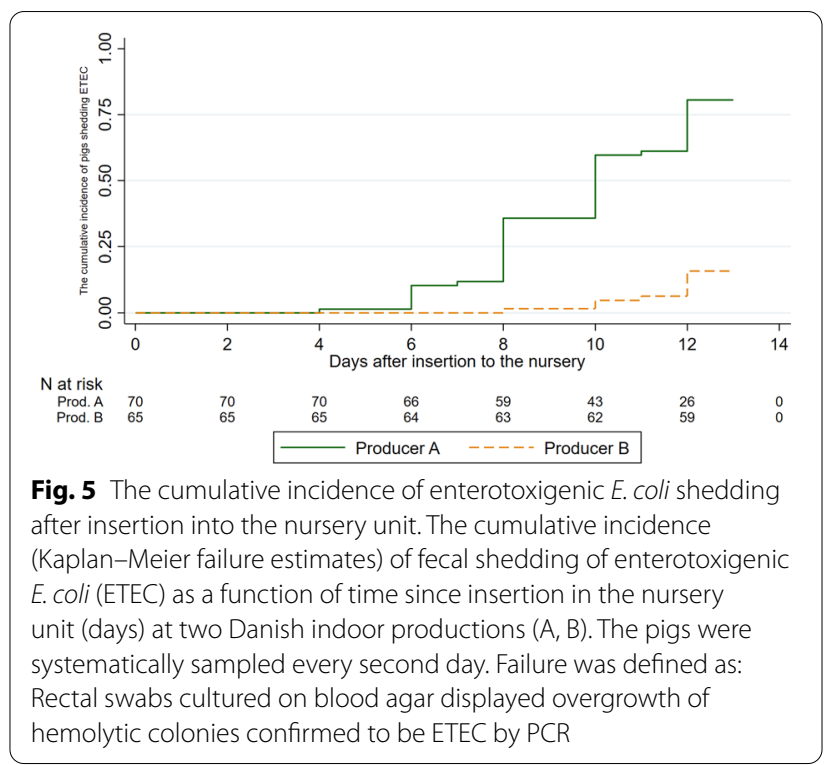


Table 3 Incidence rate ratios of diarrhea cases in pigs shedding E. coli with different virulence factors

\begin{tabular}{|c|c|c|c|c|c|c|}
\hline \multirow[b]{2}{*}{$\begin{array}{l}\text { Baseline incidence rate } \\
\text { (constant) }\end{array}$} & \multirow[t]{2}{*}{ Cases/pig days } & \multirow{2}{*}{$\begin{array}{l}\text { Incidence rate ratio } \\
0.06\end{array}$} & \multicolumn{2}{|c|}{ 95\% Confidence Interval } & \multirow{2}{*}{$\begin{array}{l}\text { Std. Err } \\
0.02\end{array}$} & \multirow{2}{*}{$\frac{\boldsymbol{p} \text { value }}{5.5 \mathrm{e}^{-22}}$} \\
\hline & & & 0.03 & 0.11 & & \\
\hline \multicolumn{7}{|l|}{ Producer } \\
\hline Producer A & $12 / 415$ & 1.00 (base) & & & & \\
\hline Producer B & $18 / 385$ & 3.78 & 1.85 & 12.83 & 2.41 & 0.001 \\
\hline \multicolumn{7}{|l|}{ Virulence factors } \\
\hline $\mathrm{H}+, \mathrm{F}+\mathrm{T}+$ & $17 / 209$ & 1.00 (base) & & & & \\
\hline $\mathrm{H}+, \mathrm{F}-, \mathrm{T}+$ & $1 / 5$ & 1.87 & 0.25 & 14.24 & 1.94 & 0.544 \\
\hline $\mathrm{H}+, \mathrm{F}+, \mathrm{T}-$ & $11 / 150$ & 0.25 & 0.09 & 0.68 & 0.13 & 0.007 \\
\hline $\mathrm{H}+, \mathrm{F}-, \mathrm{T}-$ & $2 / 48$ & 0.10 & 0.033 & 0.01 & 0.11 & 0.033 \\
\hline $\mathrm{H}-$ & $0 / 361$ & $N A^{a}$ & & & & \\
\hline
\end{tabular}

Incidence rate ratios were estimated with a Poisson regression model. E. coli was cultured from rectal swabs collected from a cohort of piglets raised at two commercial Danish indoor producers. Data was included from the seventh to the 14th day after insertion to the nursery units

$\mathrm{H}+/ \mathrm{H}-$, hemolytic $E$. coli positive/negative; $\mathrm{F}+/ \mathrm{F}-$, fimbria positive/negative; $\mathrm{T}+/ \mathrm{T}-$, toxin positive/negative

${ }^{a}$ Incidence rate was 0

the diagnosis unknown etiology. Table 4 summarizes the number of diarrhea cases with different assumed etiologies and their mean time-to-occurrence in days. In nursery $\mathrm{A}$, rotavirus $\mathrm{A}$ was the dominating etiology being detected in 38 cases (64.4\%). In Nursery B, an abundant growth of hemolytic non-ETEC E. coli was commonly seen $(n=32,47.7 \%)$ in association with the first diarrhea case. The incidences and dynamics of different etiologies are seen from the plots of Kaplan-Meier failure estimates divided on the different etiologies in Fig. 6. Clearly, the first week was dominated by rotavirus-associated cases (median time-to-occurrence $=3$ days, Table 4 ). In the second week, the incidence of diarrhea associated to ETEC (nursery A) and hemolytic non-ETEC E. coli (nursery B) accelerated. Meanwhile, rotavirus was rarely detected in high quantities $(\mathrm{CT}<33)$ in the diarrheic pigs and never as the sole pathogen.

\section{Time to cure}

The time to cure after the first diarrhea event is summarized in Table 5 . The cure-rate was similar across both producers and assumed etiology. Just over half of the piglets were already cured 1 day after the treatment initiation, and almost all pigs were cured within 3 days.

\section{Risk factors for post-weaning diarrhea}

A Cox proportional hazards model was fitted with the time-at-risk starting at the first clinical examination at the day of insertion. Thus, only the pigs which were non-diarrheic at this time point could enter the

Table 4 Time-to-event and producer-wise distribution of first cases of post-weaning diarrhea with different assumed etiologies

\begin{tabular}{|c|c|c|c|c|c|c|c|}
\hline \multirow[t]{2}{*}{ Assumed etiology at first cases of diarrhea } & \multicolumn{3}{|c|}{ Time to diarrhea event (days) $^{a}$} & \multicolumn{2}{|c|}{ Producer A } & \multicolumn{2}{|c|}{ Producer B } \\
\hline & 25th pctl & Median & 75th pctl & $\mathbf{n}$ & $\%$ & $\mathbf{n}$ & $\%$ \\
\hline ETEC & 9 & 10 & 11.25 & 12 & 20.3 & 2 & 3 \\
\hline Hemolytic non-ETEC E. coli & 7.5 & 10 & 11 & 1 & 1.7 & 23 & 34.3 \\
\hline Rotavirus A & 2 & 3 & 4 & 34 & 57.6 & 13 & 19.4 \\
\hline ETEC and rotavirus $A$ & 7 & 10 & 11 & 3 & 5.1 & 2 & 3 \\
\hline Hemolytic non-ETEC E. coli and rotavirus A & 4.5 & 6 & 8.75 & 1 & 1.7 & 9 & 13.4 \\
\hline No detection of hemolytic E. coli, ETEC or rotavirus $A^{b}$ & 3 & 6 & 11 & 5 & 8.5 & 11 & 16.4 \\
\hline Unknown etiology (missing data) & 3 & 5 & 11 & 3 & 5.1 & 7 & 10.5 \\
\hline
\end{tabular}

Summary of post-weaning diarrhea cases with different assumed infectious etiologies occurring in a cohort of piglets followed for 14 days after insertion into two Danish indoor nursery units. Data is presented as the median, 25th and 75th percentiles of the time to first diarrhea event, and as the number and percentage of first events of diarrhea at the two different producers (producer $A$ and $B$ )

${ }^{a}$ The prevalent cases at the day of insertion were not included in the calculations

${ }^{b}$ Rotavirus, hemolytic E. coli \& ETEC were detected in some of these pigs, but below the defined threshold $(C T>33)$ or the semi-quantitative criteria for dominance 


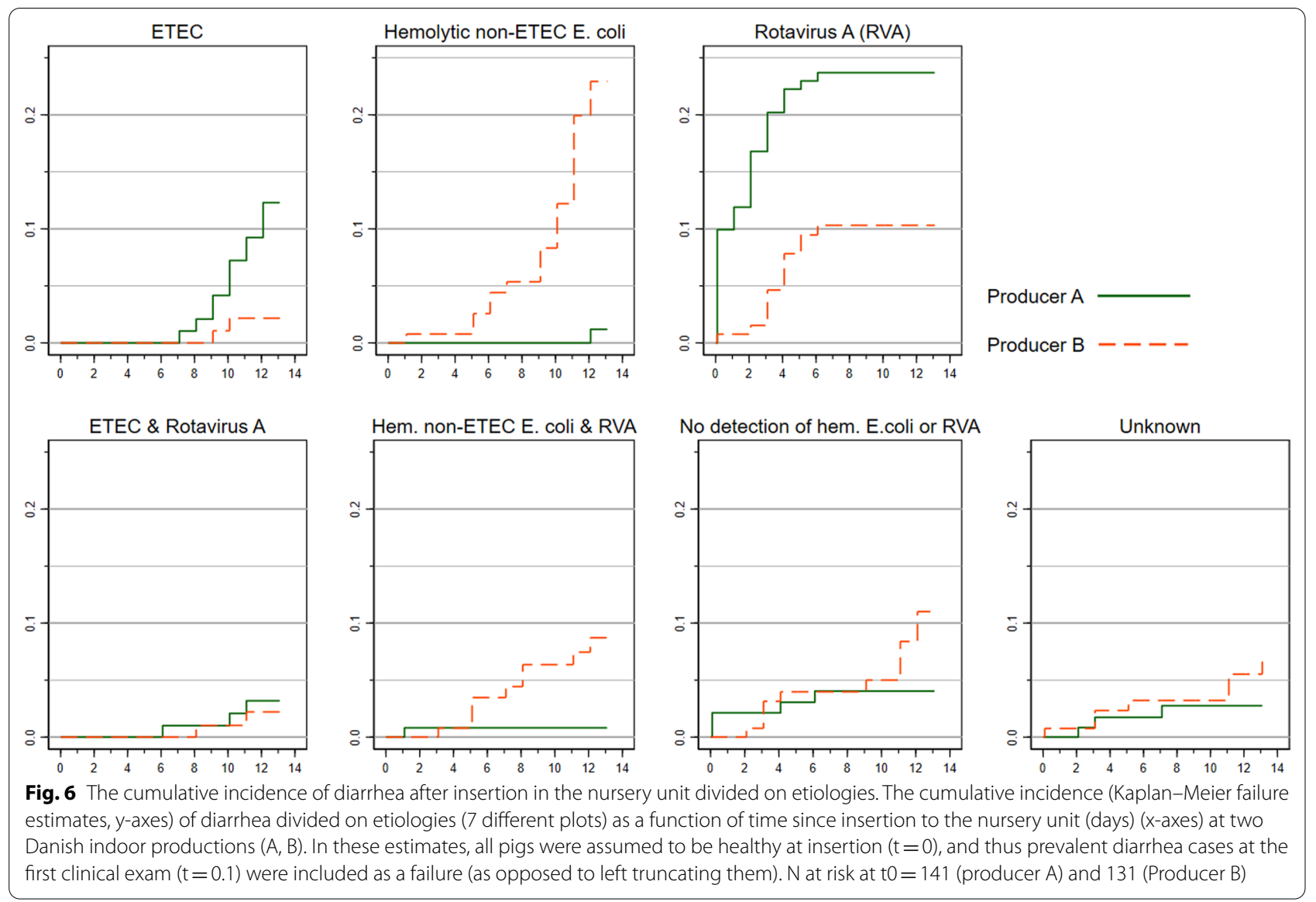

Table 5 Proportion (standard error) of pigs cured from postweaning diarrhea after a given of number days

\begin{tabular}{lllll}
\hline & $\mathbf{1}$ day & $\mathbf{2}$ days & $\mathbf{3}$ days & $\mathbf{4 - 8}$ days \\
\hline $\begin{array}{c}\text { By producer } \\
\begin{array}{c}\text { Producer A } \\
(\mathrm{n}=38)\end{array}\end{array}$ & $0.61(0.079)$ & $0.91(0.034)$ & $0.997(0.003)$ & 1 \\
$\begin{array}{c}\text { Producer } B \\
(\mathrm{n}=59)\end{array}$ & $0.53(0.065)$ & $0.85(0.036)$ & $0.98(0.010)$ & $\begin{array}{l}>0.998 \\
(<0.002)\end{array}$ \\
$\begin{array}{c}\text { By etiology } \\
\text { ETEC }(n=14)\end{array}$ & $0.5(0.13)$ & $0.95(0.045)$ & $0.995(0.007)$ & $>0.999(0.002)$ \\
$\begin{array}{c}\text { Hemolytic } \\
\text { non-ETEC E. } \\
\text { coli }(n=24)\end{array}$ & $0.5(0.10)$ & $0.82(0.064)$ & $0.96(0.025)$ & $>0.993(0.059)$ \\
$\begin{array}{c}\text { Rotavirus A } \\
(n=25)\end{array}$ & $0.48(0.10)$ & $0.79(0.65)$ & $0.98(0.012)$ & 1 \\
\hline
\end{tabular}

The cure-ratios were estimated using a Kaplan-Meier failure function. The estimates were stratified by producer ( $\mathrm{A}$ or $\mathrm{B}$ ) and by three different assumed infectious etiologies

study $(\mathrm{n}=252$, failures $=107$, pig days at risk $=2594)$. Dam was included as shared frailty effect in the model, and the coefficients from this analysis is presented in Table 6. The covariate Producer was omitted as all the between-producer variance was taken up by the Pen covariate. Low birth weight $(<1100 \mathrm{~g})$ and being offspring from young sows were revealed to be possible risk factors. Initial model-building revealed that the assumption of proportional hazards was violated for the covariate time of weaning, and therefore was made a time-varying effect; being weaned in the farrowing unit had a protective effect the first 8 days after insertion $(\mathrm{HR}=0.11)$. This tendency is clear from Fig. 7 displaying a plot of the Kaplan-Meier failure estimates stratified on time of weaning at each producer. The hazard rate was approximately constant for pigs that were weaned at the day of insertion (dashed orange curves, Fig. 7). At time 0.1, the hazard rate was high for pigs weaned in the farrowing unit, especially in nursery A. Apart from these prevalent diarrhea cases at the day of insertion (which were not included in the model), the pigs weaned in the farrowing unit had a low hazard rate until the eighth day after insertion at both producers (Fig. 7. From day eight and onwards, failures of the early-weaned pigs started to follow the same pattern as pigs weaned at the scheduled day of insertion (Fig. 7). The pseudo- $\mathrm{r}^{2}$ for the model was 0.346 (CI: 0.258 , 
Table 6 Estimates from a Cox proportional hazards model exploring the hazard of developing post-weaning diarrhea

\begin{tabular}{|c|c|c|c|c|c|}
\hline & Hazard ratio & Std. err & $p$ value & $\begin{array}{l}95 \% \text { conf. } \\
\text { interval }\end{array}$ & \\
\hline \multicolumn{6}{|l|}{ Birth weight } \\
\hline Normal-high (1110-2080 g) & 1.00 & (Base) & & & \\
\hline Low (540-1100 g) & 2.30 & 0.57 & 0.001 & 1.41 & 3.74 \\
\hline \multicolumn{6}{|l|}{ Time of weaning } \\
\hline Weaned at day of insertion to nursery & 1.00 & (Base) & & & \\
\hline Weaned in the farrowing unit, $0-7$ days post insertion & 0.11 & 0.06 & $2.3 e^{-5}$ & 0.04 & 0.30 \\
\hline Weaned in the farrowing unit, 8-13 days post insertion & 0.84 & 0.26 & 0.569 & 0.46 & 1.53 \\
\hline Dam parity & 0.88 & 0.05 & 0.041 & 0.78 & 0.99 \\
\hline \multicolumn{6}{|l|}{ Pen in the nursery (producer, mean body weight at insertion) } \\
\hline $1(\mathrm{~A}, 8.1 \mathrm{~kg})$ & 1.00 & (base) & & & \\
\hline $2(\mathrm{~A}, 6.5 \mathrm{~kg})$ & 0.53 & 0.24 & 0.153 & 0.22 & 1.27 \\
\hline $3(\mathrm{~A}, 4.2 \mathrm{~kg})$ & 0.16 & 0.08 & $3.5 e^{-4}$ & 0.06 & 0.44 \\
\hline $4(\mathrm{~A}, 5.5 \mathrm{~kg})$ & 0.61 & 0.23 & 0.196 & 0.28 & 1.29 \\
\hline $5(\mathrm{~B}, 4.8 \mathrm{~kg})$ & 0.82 & 0.31 & 0.605 & 0.39 & 1.73 \\
\hline $6(\mathrm{~B}, 6.5 \mathrm{~kg})$ & 0.62 & 0.23 & 0.199 & 0.30 & 1.29 \\
\hline $7(\mathrm{~B}, 6.5 \mathrm{~kg})$ & 0.82 & 0.32 & 0.607 & 0.39 & 1.74 \\
\hline $8(\mathrm{~B}, 8.4 \mathrm{~kg})$ & 1.18 & 0.42 & 0.652 & 0.58 & 2.39 \\
\hline
\end{tabular}

Piglets ( $n=251)$ were followed during first 14 days after insertion in two nursery units at commercial Danish indoor producers

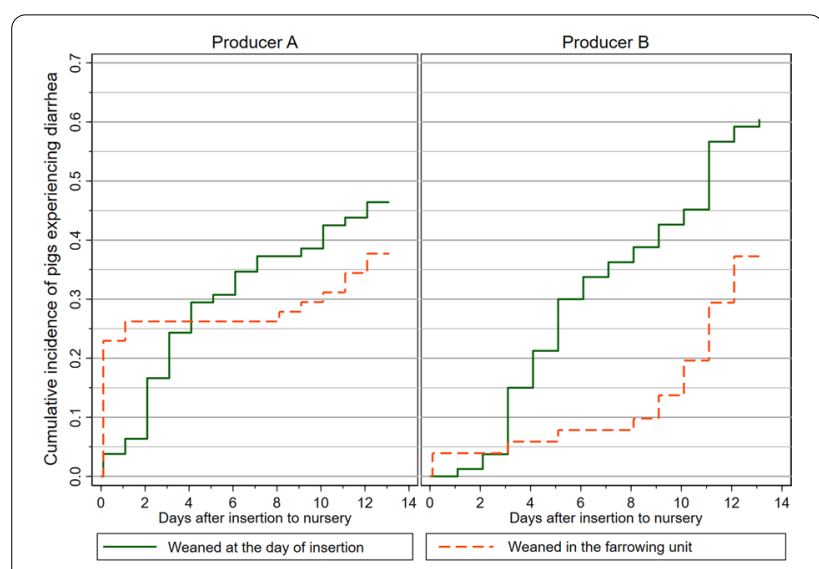

Fig. 7 The cumulative incidence of diarrhea divided on time of weaning. The cumulative incidence of diarrhea (Kaplan-Meier failure estimates) as a function of time since insertion in the nursery unit (days) at two Danish indoor productions (A and B). The curves are grouped by the time of weaning, i.e. pigs weaned at the day of insertion (green solid curve) and pigs weaned in the farrowing unit 2-6 days before insertion (dashed orange curve). All pigs ( $n=141$ and 131) were assumed to be non-diarrheic at the time of insertion (time $=0$ ), and the first clinical exam was performed at time $=0.1$

0.523), indicating that the model had a moderate ability to explain the variance in the data.

\section{Average daily weight gain}

A mixed effects linear regression model explored the factors explaining weight gain. The final model contained seven fixed effects listed in Table 7 , and Sow/pen before weaning was selected (over dam) as the random effect. None of the tested interactions were kept in the model. The model explained just over half $(52.0 \%)$ of the total variation in average daily weight gain. Producer explained a large part of the variation in the weight gain ( $35.5 \mathrm{~g} /$ day). Pigs were allocated to pens according to their approximate body size at insertion to the nursery, and therefore some of the variation explained by pen in nursery could be related to weight at insertion. Having diarrhea in 2 days or more was associated with an increased growth rate of approximately $26 \mathrm{~g} /$ day. The coefficient for weight at birth was $0.052 \mathrm{~g} /$ day. This means that the average daily weight gain will increase $5.2 \mathrm{~g}$ if the birth weight increases $100 \mathrm{~g}$. If applying this coefficient with all other predictors being equal, the heaviest piglet (birth weight: $2080 \mathrm{~g}$ ) would have an increase in daily weight gain of $81.1 \mathrm{~g} /$ day compared to the lightest piglet surviving to the end of the study (birth weight: $540 \mathrm{~g}$ ). Having low body condition score at insertion or being weaned in the farrowing unit predicted substantial increases of the growth rate, but the confidence intervals indicated a wide span of uncertainty for these estimates. The clinical sign hollow flanks was frequently observed in both nursery A ( $\mathrm{n}=494,26.0 \%$ CI $24.0,28.0)$ and nursery B $(n=872,48.9 \%$ CI $46.6 \%, 51.3 \%)$. 
Table 7 Mixed effects linear regression explaining the average daily weight gain (g/day)

\begin{tabular}{|c|c|c|c|c|}
\hline \multirow[b]{2}{*}{ Ran. effect: Sow/pen at weaning } & \multirow[t]{2}{*}{ Coefficient (g/day) } & \multirow{2}{*}{$\begin{array}{l}\boldsymbol{p} \text { value } \\
8.0 \mathrm{e}^{-4}\end{array}$} & \multicolumn{2}{|c|}{$95 \%$ confidence interval } \\
\hline & & & & \\
\hline Constant & 94.3 & $1.1 e^{-5}$ & 52.3 & 136.3 \\
\hline \multicolumn{5}{|l|}{ Producer } \\
\hline Producer A & Baseline & & & \\
\hline Producer B & 35.5 & 0.006 & 10.3 & 60.6 \\
\hline Weight at birth (g) & 0.052 & $7.6 e^{-6}$ & 0.029 & 0.075 \\
\hline \multicolumn{5}{|l|}{ Time of weaning } \\
\hline Weaned at the insertion day & Baseline & & & \\
\hline Weaned in the farrowing unit & 18.8 & 0.018 & 3.2 & 34.3 \\
\hline \multicolumn{5}{|l|}{ Body condition score at insertion } \\
\hline Normal or above & Baseline & & & \\
\hline Below normal & 20.6 & 0.016 & 3.8 & 37.4 \\
\hline Days with hollow flanks & -7.3 & $1.0 e^{-14}$ & -9.1 & -5.4 \\
\hline \multicolumn{5}{|l|}{ Days suffering from diarrhea } \\
\hline 0 days & Baseline & & & \\
\hline 1 days & 3.7 & 0.641 & -11.8 & 19.1 \\
\hline 2 days & 26.0 & 0.001 & 10.7 & 41.2 \\
\hline 3 days & 28.4 & 0.004 & 9.2 & 47.6 \\
\hline 4-6 days & 23.2 & 0.052 & -0.2 & 46.7 \\
\hline \multicolumn{5}{|l|}{ Pen in the nursery ${ }^{\mathrm{a}}$} \\
\hline $1(\mathrm{~A}, 8.1 \mathrm{~kg})$ & Baseline & & & \\
\hline $2(\mathrm{~A}, 6.5 \mathrm{~kg})$ & 7.7 & 0.493 & -14.3 & 29.7 \\
\hline $3(\mathrm{~A}, 4.2 \mathrm{~kg})$ & 0.9 & 0.951 & -26.8 & 28.5 \\
\hline $4(\mathrm{~A}, 5.5 \mathrm{~kg})$ & -20.4 & 0.073 & -42.6 & 1.9 \\
\hline $5(\mathrm{~B}, 4.8 \mathrm{~kg})$ & -16.2 & 0.196 & -40.7 & 8.3 \\
\hline $6(\mathrm{~B}, 6.5 \mathrm{~kg})$ & 1.2 & 0.918 & --21.1 & 23.5 \\
\hline $7(\mathrm{~B}, 6.5 \mathrm{~kg})$ & 19.7 & 0.091 & -3.1 & 42.6 \\
\hline $8(\mathrm{~B}, 8.4 \mathrm{~kg})$ & 0.0 & & & \\
\hline
\end{tabular}

Average daily weight gain was measured for the first 14 days after insertion to the nursery pigs units at two Danish indoor producers. $n=258$

${ }^{a}$ Pen number (producer, mean weight at insertion)

\section{Discussion}

This study estimated the cumulative incidences of diarrhea associated with $E$. coli and rotavirus A during the first 14 days after insertion to the nursery units in two Danish intensive indoor productions weaning without medicinal zinc oxide. Three risk factors for PWD were indicated, and several factors, including days suffering from diarrhea, explained the variance in growth rate. In the following paragraphs, we interpret our findings and discuss the possible implications for prudent use of antimicrobials and PWD prevention strategies. Finally, we discuss some of the limitations of the study.

\section{Interpretation of findings}

\section{Assumed etiologies and pathogen dynamics}

The present study demonstrated two interesting cases of infection dynamics in PWD outbreaks in pigs where neither antibiotics nor medicinal zinc were used as a preventive measure. The vast majority of diarrhea cases occurring during the first week after insertion to the nursery were associated with rotavirus A. We suggest that the predisposing factors reviewed in the introduction such as change of diet, post-weaning anorexia, and loss of local lactogenic mucosal immunity against rotavirus $\mathrm{A}$ have allowed the virus to flourish in these pigs. Being weaned in the farrowing unit seemed to be a protective factor $(H R R=0.11)$ the first week after insertion to the nursery (Table 6), where rotavirus-associated diarrhea dominated (Fig. 6). We hypothesize that pigs being weaned in the farrowing unit have already experienced rotavirus associated diarrhea, and started to develop immunity at the time of insertion. This explanation is supported by the large proportion of pigs with prevalent rotavirus-associated diarrhea at the time of insertion in nursery A. Future epidemiological studies of PWD in productions with frequent use of foster sows (and thus 
irregular weaning) should therefore examine pigs from the exact time of weaning rather than insertion to the nursery.

Most of the diarrhea cases were not associated with ETEC detection. Especially in nursery B, ETEC was rarely detected, but instead a large proportion of diarrhea cases was associated with substantial excretion of hemolytic $E$. coli where none of the three major toxins in ETEC were detected. This could reflect a mere association confounded by time since weaning, rather than a causal relation, but our Poisson regression (model 3) estimated an increased incidence rate of diarrhea in pigs shedding hemolytic E. coli without toxins, and even higher rate in pigs shedding ETEC (Table 3). Results in accordance with this, was found in early experimental study of the role of virulence factors in porcine colibacillosis where E. coli strains were modified using plasmids. Oral inoculation with $E$. coli carrying both enterotoxins and fimbria frequently $(n=20 / 25)$ produced severe diarrhea in day-old piglets, while strains lacking these virulence factors did not produce disease $(\mathrm{n}=0 / 8)$. Interestingly, $E$. coli only carrying fimbria, but not enterotoxins, also produced disease but with a lower morbidity $(n=6 / 20)$ and severity [38]. A frequent occurrence of PWD with no detection of ETEC has previously been demonstrated in a European survey including samples from 844 pigs. ETEC was not detected in $59.6 \%$ of the 280 investigated farms/PWD outbreaks [11]. This increasing evidence of post-weaning without ETEC-detection is contradicting the common perception of the disease etiology. In a series of semistructured interviews, Danish pig producers and veterinarians commonly referred to PWD as "coli-diarrhea" [39].

Intestinal dysbiosis has been defined as, "a marked decrease in the representation of obligate anaerobic bacteria and an increased relative abundance of facultative anaerobic bacteria belonging to the family Enterobacteriaceae" [40]. Thus, the high fecal excretion of hemolytic $E$. coli could possibly be an indicator of an intestinal dysbiosis. Gut inflammation provides a nitrate rich environment, making nitrate-reducing $E$. coli thrive, and by this mechanism gut inflammation has been hypothesized to cause the shift towards Enterobacteriaceae termed dysbiosis [40]. Gresse et al. [4] refined the hypothesis on causation and suggested that weaning-induced dysbiosis and gut inflammation interplays and enhances each other in an escalating vicious circle. Independently of whether their increased abundance is a cause or an effect, hemolytic E. coli could still serve as an indicator for dysbiosis. Hence, the diarrhea cases associated with substantial excretion of hemolytic E. coli could be caused by a dysbiosis by the pathogenesis suggested by Gresse et al. [4]
As previously suggested [41] this calls for studies integrating recordings of the gut microbiome, metabolome and pathology to disentangle the causal webs of postweaning gut health and disease. It may also be that the hemolytic non-ETEC E. coli carry a toxin, which has so far not been associated with PWD. For example, a high proportion of $E$. coli from PWD in Denmark has been shown to carry the astA gene, encoding the enteroaggregative $E$. coli heat-stable enterotoxin (EAST1) [42]. However, the pathogenicity of this toxin is unclear, and the available research indicates that it is not contributing to the development of porcine PWD [43, 44].

Taken together, our microbiological findings are in agreement with three previous studies demonstrating rotavirus shortly after weaning followed by proliferation of hemolytic E. coli $[14,45,46]$ even though the shedding of rotavirus was delayed and occurred after proliferation of hemolytic E. coli in one of the two trials reported by Hampson and Smith [46].

\section{Risk factors for post-weaning diarrhea}

Our data suggested that piglets with low birth weight and offspring of younger sows have increased risk of PWD. Given the limited sample size and our explorative model building strategy, the study does not provide conclusive evidence. Yet, both findings are biologically meaningful. For instance, it is well-established that low birth weight is predisposing for many negative health outcomes such as pre-weaning mortality [47]. Multiple studies have investigated herd-level risk factors for PWD (e.g. [48, 49]), but to our knowledge, research exploring (early-life) risk factors for PWD at individual pig-level have been sparse prior to our study. A review paper from 2017 dealt with risk factors for E. coli-associated PWD, but the statements about factors related to the individual pig (e.g. parity of the dam) were founded in a generalization of evidence about preweaning health [50]. Dou et al. [51] had reported differences in the gut microbiota 7 days after birth in 13 pigs that experienced PWD compared to seven pigs that stayed healthy throughout the post-weaning period. Therefore, a specific motivation for the present study was to collect evidence clarifying the hypothesis, that pre-weaning diarrhea increases the risk of experiencing PWD in an individual pig. However, few piglets $(n=7$, $2.5 \%)$ had pre-weaning diarrhea recorded, and in line with this, the post-mortem exams revealed that gastrointestinal lesions were infrequently assigned as the primary cause of death in the pre-weaning period. Consequently, the data material did not allow us to make inferences regarding the effect of pre-weaning diarrhea on the risk/hazard of developing PWD. 


\section{Growth rate}

A previous study has shown that the pen-level occurrence of PWD was negatively associated to the average weight gain of the piglets within the pens [48]. Our study of individual pigs was contradicting this, at least for pigs having diarrhea for more than just a single day. A reasonable explanation could be that high feed intake ("overeating") confounds the association, as it both increases the risk of post-weaning diarrhea [46] and improves growth. It should also be noted that it is actually the combined effect of suffering from diarrhea and receiving antimicrobials we have studied. Both of the suggested explanations call for further research.

The observed influence of birth weight on growth rate likely reflects the importance of genetic factors as well as a long-term negative impact of intrauterine growth restriction, which is strongly associated with low birth weight [52]. Piglets with low birth weight, and/ or intrauterine growth restriction syndrome are known to have poor growth, impaired ability to resist disease and a higher pre-weaning mortality [52-55]. The piglets weaned before the insertion day had a higher growth rate than piglets weaned at the day of insertion. This might reflect that the farm personnel picked the most robust piglets (with best growing potential) for early weaning. Furthermore, weaning is often accompanied with a period of adaption (to new feed etc.) leading to poor or negative weight gain $[56,57]$. The pigs weaned in the farrowing unit had already been through these first challenging days when they were inserted to the nursery. This explanation was echoed in a negative average growth rate during the few [1-6] days from weaning to insertion to the nursery in the early-weaned pigs (mean: $-5.3 \mathrm{~g} /$ day, SD: 91.0, results not shown). The explanation would also be in line with the finding that Body condition score below normal at the day of insertion was associated with an increased growth rate. We hypothesize that pigs with poor body condition score have been diseased or living under suboptimal conditions prior to insertion to the nursery e.g. staying with a sow with poor milk production or have been weaned in the farrowing unit (weaned in farrowing unit was associated with BCS below normal at insertion: Crude relative risk $=2.4, p=0.005)$. These pigs might prosper after insertion to the nursery where they will benefit from the liberal feed availability or that they have already lived through the toughest first days after weaning. Evidence of such compensatory growth have been presented previously. Huting et al. [58] showed that pigs with intermediate or high birth weight, but low weaning weight, had higher odds of being heavy at the age of 99 days compared to pigs with low birth weight.

Hollow flanks is, to the authors' knowledge, commonly interpreted by pig practitioners as a sign of lacking feed intake in weaners and growers. The results indicated that this interpretation is reasonable, as the variable was associated with a decreased average daily weight gain.

\section{Implications for prudent antimicrobial use and prevention strategies}

The present study demonstrated two cases of PWD outbreaks, where the justification for oral batch medication with antimicrobials was questionable. A substantial proportion of the pigs stayed healthy, a large proportion of the cases were associated with a non-bacterial pathogen (rotavirus), and only a minority of the cases were associated with the pathogenic bacterial agent (ETEC) that was the indication for the veterinarians' prescriptions and the producers' common initiation of oral antimicrobial batch medications. Antimicrobials affect the gut microbiota composition [59] and by this mechanism, some might advocate that treatment could hypothetically relieve clinical disease associated with dysbiosis and therefore they should still be administered. Even if future research was to support this hypothesis, we argue that prudent use entails promotion of gut symbiosis and health by alternative measures, and reserving antimicrobials for treatment of diseases caused by a bacterial infection. In essence, our study has a sample size of $n=2$, when inferring about diarrhea outbreaks as a whole. To which extent the etiologic and disease dynamic patterns, like the two seen in this study, are prevalent across the population of nursery pig units is unknown. Nevertheless, the study demonstrated the existence of PWD outbreaks where ETEC did not play a major role as causative agent.

The study also demonstrated that outbreaks of PWD might have a biphasic pattern. In both productions, we saw two peaks in diarrhea prevalence, where rotavirus dominated at first followed by $E$. coli-associated cases. Another study has demonstrated a high within-herd between-batch variation of the three dominating pathogens (Lawsonia intracelluaris, Brachyspira pilosicoli and ETEC) in outbreaks of porcine intestinal disease in nursery pigs 10-70 days after weaning [34]. Consequently, the necessity of frequent microbiological laboratory diagnostics to appropriately select antimicrobial substance has been proposed [60]. The two cases of within-outbreak shift in dominating etiology presented in this paper further complicates diagnosing and treating intestinal diseases in flocks of pigs. Practitioners must not only consider between-outbreak variation in pathogens, but also shifts within (what could be perceived as) one outbreak in a given batch.

The risk factors proposed by our Cox model, suggest that taking extra care for offspring of younger sows and with low birthweight could aid the control of PWD. Previous studies have concluded that it is beneficial to sort 
piglets based on litters rather than body weight. This will reduce aggression and stress, and the resulting gastrointestinal tract impairment in the early post-weaning period (reviewed by $[9,56])$. Our findings demonstrated that disease dynamics might be different between piglets weaned in the farrowing unit, and piglets weaned at the day of insertion to the nursery. Therefore, it could be advisable to sort early-weaned litters into designated pens in the nursery. This might increase the chance of a synchronized course of gut development and infections within a pen. This synchronization could both lower the load of circulating pathogens and increase the possibility of making well-timed metaphylactic treatments. As such, this is a proposal worth to investigate in further research or in herd-specific trials conducted as part of the continuous development of the management at a given farm (e.g. as suggested in [61]).

\section{Limitations of the study}

A limitation to the present study is the relatively small sample size. Furthermore, our regression model building was explorative, in the sense that we fitted models that best described the collected data, rather than testing whether our data fitted a pre-specified hypothesized model. Certain features characterized the study population, e.g. injections with antimicrobials during the first day of life, and a large proportion of cross-fostered piglets. While this is representative for Danish indoor production, it might limit the generalizability to other populations.

We included 10 piglets per sow/litter $(n=30)$. By this approach, piglets from small litters had a higher probability of being included than piglets from large litters. Consequently, piglets from small litters have been overrepresented in our sample in comparison to the target population. We could have avoided this by including a fraction (e.g. half) of the pigs in each litter rather than a fixed number $(n=10)$ of pigs per litter. However, model 1 failed to suggest litter size as a possible risk factor for PWD. Further criticism might be valid for the methodology for random inclusion of pigs, which was chosen for its practicality. Even though this was not a perfect random probability sampling with enumeration of all pigs, we believe we have included a representative sample of pigs, for instance the male:female ratio and the distribution of birth weights were as expected if by random selection.

Laboratory diagnostics were conducted to determine which $E$. coli strains were shed in the feces. We presume that our approach had a satisfactory sensitivity for detection of ETEC. ETEC strains most frequently associated with PWD carry the fimbria type F4 or F18 and the toxins heat-labile toxin (LT), heat-stable toxin a (STa) and/or heat-stable toxin b $(\mathrm{STb})[11,62]$. F4 and $\mathrm{F} 18$ positive $E$. coli colonies almost always express hemolysis when cultured on blood agar, and thus genotyping hemolytic colonies is a sensitive method for detecting ETEC shedding $[63,64]$. This has been confirmed in fairly recent strains from diarrhea cases in Danish nursery pigs [65].

\section{Conclusions}

The cumulative incidences of PWD the first 14 days after insertion to nursery units not using medicinal zinc were $41.8 \%$ (CI 33.6, 50.4) and $51.1 \%$ (CI $42.3,60.0$ ) at producer $\mathrm{A}$ and $\mathrm{B}$, respectively. The occurrence of cases associated to ETEC was low, but rotavirus might be an important contributing cause to PWD. We observed a biphasic pattern in the assumed etiology with rotavirus occurring first, and then a shift towards cases associated to ETEC/non-ETEC hemolytic E. coli. Being offspring of older sows was a protective factor for the development of PWD $(\mathrm{HR}=0.88[0.78,0.99]$ per 1 unit increase in parity of the dam). Low birth weight reduced the post-weaning growth rate (-5.2 g/day [2.9-7.5] per $100 \mathrm{~g}$ decrease in birthweight) and increased the hazard of developing PWD (HR for birthweight below 1100 g: 2.30 [1.413.74]). The combined effect of having diarrhea for 2 days or more and receiving antimicrobial treatment was associated with an increase in the average daily weight gain.

\section{Methods}

The study was conducted as a cohort study. The paper was drafted to comply with the STROBE-VET guidelines [66]. A summary of the methodology is available in Fig. 8 (created using BioRender.com).

\section{Study population and setting}

A cohort of 300 piglets were followed from birth to 14 days after insertion in the nursery unit. Sample size calculation suggested that 865 pigs were necessary to show an effect of pre-weaning diarrhea on the incidence of PWD, but due to limited resources, only 300 piglets were included. The pigs were kept in two different commercial Danish intensive indoor production systems. Both producers had a multisite structure with a farrowing unit at one location and the nursery unit at another location. The producers were purposely selected among the participants in another study of the causes of PWD [67], as they fulfilled all of the following inclusion criteria: Did not use in-feed medicinal zinc oxide at weaning; experienced problems with post weaning diarrhea associated with fimbria positive E. coli; and frequently initiated antimicrobial batch medication against PWD based on clinical signs.

The study period was set to start just before an expected peak in the rate of farrowings, the 7th of September 2019 


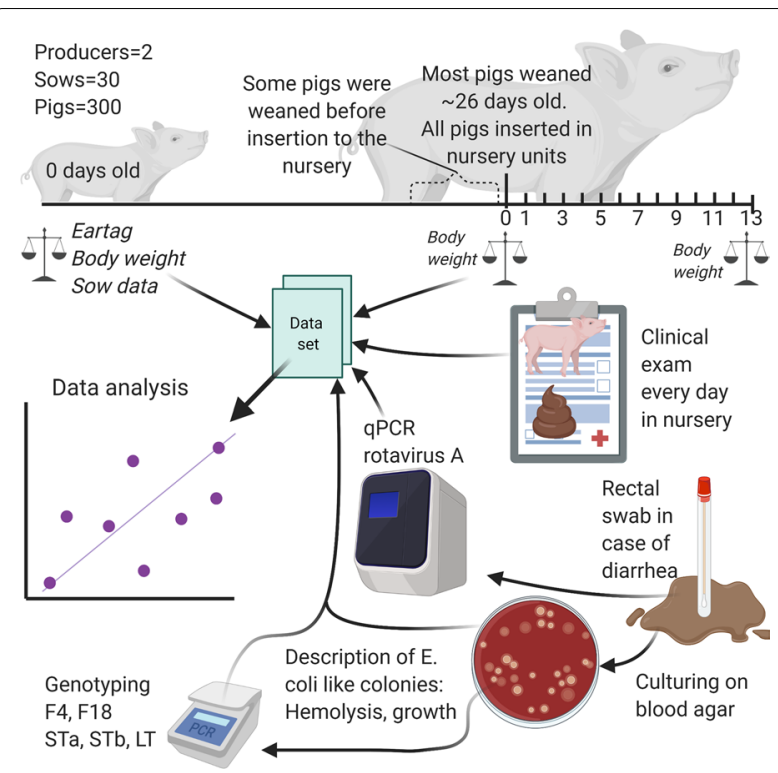

Fig. 8 Graphical abstract of the methods in a cohort study of post-weaning diarrhea in pigs. Created with BioRender.com. Pigs were weaned without medicinal zinc and prophylactic antimicrobials. The study investigated risk factors, pathogen dynamics, and association to growth rate

at producer A, and 21st of September 2019 at producer B. The source population was the first 15 litters to be born in each of the two farrowing units (30 litters in total), and the study population was obtained by randomly selecting ten piglets from each litter. The final fifteenth litter was born on the second day (8th of Sep.) at producer A and the fourth day (24th of Sep.) at producer B. The random selection was performed by collecting all piglets within a given litter in the corner of the pen. Hereafter, 10 piglets were picked up blindly. Cross-fostering and medications were not allowed before inclusion, but some piglets had died or were euthanized during the first hours of life, and these piglets were obviously not given the chance to enter the study.

The majority of the piglets were weaned at the day of insertion to the nursery unit, i.e. at the 26th and 27th day after start of the study at producer A and producer $B$, respectively. No piglets were weaned later than these days, but many piglets were weaned earlier as their sow was selected to be a foster sow. These early-weaned piglets stayed in the farrowing units, either in a climate controlled section provided for this purpose (producer A) or in their farrowing pens (producer B), until the day of common weaning. At this day, all included pigs were collectively transported to the nursery unit of the respective producer. At each production site, the pigs were allocated to four pens with approximately 30-35 pigs. The pigs were sorted by approximate body size, as it was usual practice in both nursery units, and no pigs were moved during the study period.

\section{Records and sampling}

At the day of birth, the piglets were weighed and their sex recorded. Parity and litter size were noted for the dams. The farm personnel took care of the piglets during the suckling period and registered an indication for treatment before any antimicrobial treatments were initiated. Piglets were weighed at insertion in the nursery and at death or at censoring (i.e. 14 days after insertion to the nursery at the end of the study-period). Fecal consistency [68] and clinical signs were recorded for all pigs every day after insertion in the nursery section. A dichotomous scoring of fecal consistency (diarrhea yes/ no) was made based on the appearance of the feces on a rectal swab [69], and if the pig spontaneously defecated, this was taken into account as well. When a new case of diarrhea arose, the given pig was subjected to 3 days of individual oral medication (SID) with neomycin sulfate (Neomay, ScanVet) $25.000 \mathrm{UI} / \mathrm{kg}$ body weight/day. If a pig still displayed diarrhea at the end of this treatment, the medication was prolonged for an additional 3 days.

\section{Necropsy}

All piglets that died in the pre-weaning period underwent post-mortem investigation at the Department of Veterinary and Animal Sciences, at the University of Copenhagen. The piglets were stored in a cool room at the farm until collection for necropsy, twice a week. The pigs were subjected to a total necropsy as previously described [70]. All lesions were recorded. All piglets were assigned one primary cause of death based on the lesions recorded, although several pathological manifestations could be present in individual pigs.

\section{Microbiology \\ Sampling}

Whenever a new case of diarrhea was observed, a rectal swab was collected for microbiological analyses. In addition, half of the piglets (even ear tag numbers, $n=75$ at each producer, $\mathrm{n}=150$ in total) were repeatedly sampled for microbiological analyses of their rectal contents irrespective of their fecal consistency. A rectal swab was collected from this sub-cohort routinely every second day (day $0,2 \ldots 12$ ) during the first 14 days after the day of insertion into the nursery unit. For practical reasons, this systematical sampling was performed at day -1 (i.e. the last day in the farrowing unit) instead of day 0 at producer A. All rectal swabs were immediately placed in $1 \mathrm{~mL}$ Amies medium (ESwab ${ }^{\mathrm{TM}}$, COPAN Diagnostics Inc.). The samples were stored in a refrigerator in the herd, and transported to the laboratory at University 
of Copenhagen two times weekly. At arrival, a $200 \mu \mathrm{l}$ subsample was frozen at $-80^{\circ}$ Celsius for rotavirus A detection.

\section{Bacteriology}

At arrival of the sample, $10 \mu \mathrm{l}$ was plated out on a blood agar (agar base supplemented with $5 \%$ calf blood) using an inoculation loop and incubated at $37^{\circ} \mathrm{C}$ for $24 \mathrm{~h}$. Subsequently, a visual screening for hemolytic $E$. coli-like colonies was performed. To be considered E. coli, colonies had to be greyish-white, medium to large size and mucoid. In any case of doubt, the $E$. coli classification was confirmed by Matrix-Assisted Laser Desorption Ionisation Time-Of-Flight (MALDI-TOF) mass spectrometry [71]. Hemolytic ability, growth extent, and relative abundance compared to other colony types were described for the most dominant hemolytic $E$. coli-like phenotype on the agar plate. A colony of the most dominant $E$. coli phenotype was picked and plated out on another blood agar for purification. If no hemolytic colony was present, the most dominant non-hemolytic E. coli-like phenotype was described and purified. Once purified, the cultures were frozen $\left(-80{ }^{\circ} \mathrm{C}\right)$ in Brain Heart Infusion broth supplemented with $30 \%$ glycerol. Hemolytic $E$. coli were further subjected to DNA isolation and multiplex PCR according to a previously described procedure [72] with minor modifications. A total volume of $25 \mu \mathrm{l}$ PCR reaction mix was prepared as follows: $0.5 \mu \mathrm{l}$ of each F4(K88), F18, LT, $\mathrm{STa}$ and STb forward and reverse primers at a concentration of $100 \mu \mathrm{M}$ were mixed with $12 \mu \mathrm{l}$ of DreamTaq Green PCR Master Mix (2x) (Thermofisher Scientific), $6 \mu \mathrm{l}$ of nuclease-free water and $2 \mu \mathrm{l}$ of DNA lysate. PCR was completed and products were separated on an electrophoresis gel using conditions as previously described [72].

\section{Rotavirus detection}

All samples originating from diarrhea cases were analyzed for the presence of rotavirus A. Reverse Transcription real-time PCR (RT-PCR) was carried out as previously described [73]. Nucleic acids were extracted from $200 \mu$ l Aimes medium using the Cador Pathogen 96 Qiacube HT kit [5] ref. 54161, automated on the Qiacube HT (Qiagen) according to instructions from the supplier. Three primer and probe sequences $[73,74]$ targeting rotaviral RNA were diluted in a final volume of $15 \mu \mathrm{l}$ using an AgPath-ID one-step RT-PCR reagents kit (Applied Biosystems, Foster City, USA) with $3 \mu \mathrm{L}$ RNA. RT-PCR buffer $(2 \mathrm{X})(7.5 \mu \mathrm{L})$ was mixed with $0.12 \mu \mathrm{L}$ of each primer $(50 \mu \mathrm{M}), 0.18 \mu \mathrm{L}$ probe $(10 \mu \mathrm{M}), 0.6 \mu \mathrm{L}$ RT-PCR enzyme mix (25X) and nuclease-free water. The thermal cycling conditions were $45^{\circ} \mathrm{C}$ for $10 \mathrm{~min}$, $95{ }^{\circ} \mathrm{C}$ for $10 \mathrm{~min}$, followed by 48 cycles at $95^{\circ} \mathrm{C}$ for $15 \mathrm{~s}$, and finally $60{ }^{\circ} \mathrm{C}$ for $45 \mathrm{~s}$. The fluorescence signal was obtained in the green channel during the $60^{\circ} \mathrm{C}$ step [73].

\section{Case-definitions}

The result of a bacteriological culturing should be interpret semi-quantitatively when investigating the role of $E$. coli in PWD [64]. We applied the following criteria (both must be fulfilled) to diagnose abundant of hemolytic E. coli: Growth of a hemolytic E. coli-like phenotype on at least $20 \%$ of the plate (i.e. more than a few colonies); and the considered hemolytic E. coli-like phenotype is making up approximately $50 \%$ or more of all colonies on the plate. We defined seven case definitions for the linked presentation of clinical findings and microbiology, and these are presented in Textbox 1. All criteria had to be fulfilled to get a given diagnosis.

\section{Textbox 1: Case definitions applied in the cohort study of post-weaning diarrhea}

\section{ETEC-associated diarrhea}

Diarrhea

Abundant growth of hemolytic E. coli

The considered E. coli-like phenotype is confirmed to carry genes for fimbria (F4 and/or F18) and toxins (STa, STb and/or LT)

2. Hemolytic non-ETEC E. coli associated diarrhea

Diarrhea

Abundant growth of hemolytic E. coli

The considered E. coli-like phenotype is not carrying genes for both fimbria (F4 or F18) and toxins (STa, STb, and/or LT)

\section{Rotavirus-associated diarrhea:}

Diarrhea

Ct-value $<33$ for rotavirus $A$

\section{ETEC- and Rotavirus-associated diarrhea}

Fulfills both the case-definition for ETEC-associated diarrhea and Rotavirus-associated diarrhea

5. Hemolytic non-ETEC E. coli- and Rotavirus-associated diarrhea

Fulfills both the case-definition for Hemolytic E. coli associated diarrhea Rotavirus-associated diarrhea

\section{Diarrhea with no detection of pathogens}

Diarrhea

Complete test results for both rotavirus and bacteriology is available

Does not fulfill the criteria for ETEC-associated diarrhea, hemolytic E. coli associated diarrhea, or Rotavirus-associated diarrhea

\section{Diarrhea with unknown etiology}

Diarrhea

Missing test results for either rotavirus or bacteriology, and no reasonable imputations could be made

\section{Statistical analyses \\ Descriptive statistics and simple analyses}

All statistical work was carried in Stata IC 16 [75]. The distributions of continuous variables was evaluated 
with histograms and quantile-quantile plots. Descriptive statistics including proportions and means or percentiles (in case of non-normality) were produced for all variables. Measures of disease frequency were estimated for first cases of diarrhea, and the number of second cases were calculated. A pig was considered at risk of experiencing a second case when it had experienced a first case of diarrhea, followed by at least one intermediate day without signs of diarrhea and it was least $24 \mathrm{~h}$ since the last neomycin administration. KaplanMeier failure estimate plots were created per producer for the following events after insertion to the nursery: First cases of diarrhea, first cases of diarrhea divided by the seven case definitions (i.e. assumed microbiological etiologies), shedding of hemolytic E. coli, shedding of ETEC and time of weaning. In these Kaplan-Meier estimates, all pigs were assumed to be healthy at the time of insertion to the nursery $(t=0)$, and thus prevalent diarrhea cases at the first clinical exam $(t=0.1)$ were included as a failure (as opposed to left truncating them). The Kaplan-Meier failure function was also used to summarize the time-to-cure divided on producer, and on etiologies if $n>10$ (thus only singleetiology cases). A pig was considered at risk of being cured, when it experienced its first case of diarrhea and received a subsequent antimicrobial treatment, and cure was defined as not having diarrhea at a clinical examination. Prevalent cases at the day of insertion was not included in this estimation.

\section{Regression models}

Three regression models were built (guided by [76]) to serve different scientific objectives:

Model 1 To explore whether any covariates were associated with an altered hazard of experiencing an event of PWD.

Model 2 To explore whether any factors were associated with an altered growth rate after insertion in the nursery unit.

Model 3 To explore effect of shedding E. coli with different virulence factors on the incidence rate of diarrhea cases.

Model 1: Cox model for exploration of risk factors To serve the objective of Model 1 we built a Cox proportional hazards model [77]. The time-at-risk was set to start at the time of the first clinical exam, and pigs with prevalent diarrhea at the day of insertion were not included in the analysis. Tied events were handled by the Efron method.

The covariates that were considered for the model, are listed in Table 8. To prevent multicollinearity, all covariates were evaluated pairwise for associations/ correlations. Producer and pen were controlled for by

Table 8 Variables considered for inclusion in two regression models in the cohort study of post-weaning diarrhea

\begin{tabular}{|c|c|c|c|}
\hline Variables & Scale of measurement & Model 1 (Cox PH) & Model 2 (Mixed linear) \\
\hline Producer & Dichotomous (A, B) & Covariate & Fixed effect \\
\hline Pen in nursery & Nominal $(n=8)$ & Covariate & Fixed effect \\
\hline Sow/pen before weaning & Nominal $(n=45)$ & & Random effect \\
\hline Dam & Nominal $(n=30)$ & Shared frailty & Random effect \\
\hline Dam parity & Discrete $(1-7)$ & Covariate & Fixed effect \\
\hline Total (still + live born) litter size, dam & Discrete (total n pigs 14-28) & Covariate & Fixed effect \\
\hline Proportion of litter stillborn & Proportion (0-1) & Covariate & Fixed effect \\
\hline Sex at insertion to nursery & Nominal (castrated male, intact male, female) & Covariate & Fixed effect \\
\hline Weight at birth & Continuous (grams) & Covariate & Fixed effect \\
\hline Weight at birth, dichotomized & $\begin{array}{l}\text { Dichotomous (low birth weight, normal or high birth } \\
\text { weight) }\end{array}$ & Covariate & \\
\hline Moved in the farrowing unit & Dichotomous (stayed with dam, moved) & Covariate & Fixed effect \\
\hline Time of weaning & $\begin{array}{l}\text { Dichotomous (weaned in the farrowing unit, weaned at } \\
\text { insertion to nursery) } \\
\text { A Time varying effect was added }\end{array}$ & Covariate & Fixed effect \\
\hline Weight at insertion & Continuous (grams) & Covariate & Fixed effect \\
\hline Body condition score at insertion to nursery & Dichotomous (normal, below normal) & Covariate & Fixed effect \\
\hline Days with hollow flanks & Discrete (n days with hollow flanks 0-14) & & Fixed effect \\
\hline Days suffering from diarrhea & Nominal: (0 days, 1 day, 2 days, 3 days, 4-6 days) & & Fixed effect \\
\hline
\end{tabular}

Variables considered for inclusion in two regression models investigating risk factors for porcine post-weaning diarrhea (Model 1, Cox proportional hazards model), and factors associated with altered growth rate the first 14 days after insertion to the nursery unit (Model 2, mixed linear regression model) 
adding them as covariates, and Dam was added as a shared frailty. The covariate body condition score at the day of insertion was considered an indicator of the health of the piglet at the time of insertion. Due to low variance, this predictor was dichotomized into the categories: normal or above $(89.7 \% \mathrm{n}=227)$ and below normal $(10.3 \%$, $\mathrm{n}=26$ ). The clinical signs, hair coat and general condition, were not considered due to low variability (prevalence at $\mathrm{t} 0: 1.1 \% \mathrm{n}=3$ and $0.4 \% \mathrm{n}=1$, respectively). A plot of martingale residuals indicated a non-linear tendency for birth weight: A birth weight up to approximately $950 \mathrm{~g}$ was associated with a constant, increased hazard; from approximately $950 \mathrm{~g}$ to $1300 \mathrm{~g}$ the hazard decreased; and reached a constant, lowered level when above approximately $1300 \mathrm{~g}$. Previous studies (as metaanalyzed in [47]) have demonstrated a similar trend in the risk of pre-weaning mortality, and a birthweight below $1110 \mathrm{~g}$ has been suggested as a threshold for increased risk of pre-weaning mortality [47]. Therefore, the variable was dichotomized into low birthweight (540-1100 g), and normal or high birthweight (1110-2080 g).

A backwards stepwise selection procedure was applied where covariates with $p<0.05$ were kept in the model. Excluded covariates were added back into the model one at a time to check for confounding effects. Violation of the proportional hazards assumption was checked by testing for a non-zero slope when plotting Schoenfeld residuals against time. Furthermore, parallelism of curves was graphically assessed in ln-cumulative hazard plots for categorical covariates, and by plotting Schoenfeld residuals with a smoothed line for continuous covariates. The assumption of proportional hazards was violated for weaned in the farrowing unit, and this was handled by making it a time varying effect. The linearity of relationships with continues and discrete covariates were checked by estimating martingale residuals from the final model without the covariate. Following this, the residuals were plotted against the given covariate with a lowess smoothed curve. Deviance residuals were plotted against analysis time to check for outliers. An $\mathrm{r}^{2}$ statistic $[78,79]$ was calculated to assess the variation explained by the model.

Model 2: Linear regression of effects on growth rate Model 2 was built as a multilevel mixed-effects linear regression. Only pigs that survived until 14 days after insertion and had no missing values for the considered predictors were included $(\mathrm{n}=256)$. The outcome variable was the average daily weight gain $(g)$ the first 14 days after insertion to the nursery unit. Biologically relevant covariates were considered for the model (Table 8). Sow/pen before weaning and dam were highly correlated, yet not organized in a hierarchy. Therefore, the variable that explained most of the variance in a univariable linear regression was added as a random factor and the other was excluded from the analysis. Both producer and pen in the nursery unit were controlled for by adding them as fixed effects. Two variables, hollow flanks days and diarrhea days, were created to reflect the time of the post-weaning period with low feed-intake and time suffering from diarrhea, respectively. Hollow flanks days was created by dichotomizing the observation of abdominal shape into hollow flanks/not hollow flanks (including normal and distended abdomen), as there were only two observations of abdominal distention. This variable was treated as continuous, i.e. number of days suffering from hollow flanks $(0-14)$, as a lowess smoothed curve indicated a linearity of the relationship to average daily gain. Likewise, diarrhea days summarized the number of days a given pig had suffered from diarrhea (ranging from 0 to 6 ). However, this variable was made categorical to allow the combination of 4, 5, and 6 days, as these occurred relatively infrequently $(n=9,3$, and 3 , respectively). A backwards selection procedure, and a check for confounders and interactions were performed as done for Model 1. The final model was reestimated without birth weight and time of weaning to assess if these variables were colliders between diarrhea days and weight gain. The assumptions for the model were evaluated at both pig-level and at the level of the random factor (sow/ pen before weaning). The assumption of normality of the residuals was evaluated graphically (histogram and normal quantile plot) and by Shapiro-Wilk test for normality. The homoscedasticity of the error was evaluated by plotting standardized residuals against the predicted average daily gain.

Model 3: Poisson regression exploring the importance of $E$. coli virulence factors Based on the pigs that had been systematically sampled every second day, a four-level nominal variable was created by grouping the hemolytic $E$. coli strains by the presence $( \pm)$ of fimbria, and toxins. The incidence rate ratios between the four groups were estimated with a Poisson regression model. The model was based on observations of the systematically sampled half of the cohort. The outcome variable was the count of new diarrhea cases, and both first and second cases of diarrhea were included. Producer was added as a covariate. Adding pen as random effect did not affect the model, and therefore this factor was omitted. The exposure (risk time) was measured in pig days, and a pig was not considered at risk when it had received neomycin within $24 \mathrm{~h}$. Each bacteriological culturing contributed with up to two pig days, the sampling day and the following day (unless a new sample was cultured that day). The first 6 days after insertion to the nursery, the pigs generally (622 out of 692 pig days) shed non-hemolytic E. coli, and strains with 
fimbria and/or toxins were rare (12 pig days). Therefore, time-since-insertion (and rotavirus involvement in diarrhea cases) confounded the variable describing types of E. coli. Correspondingly, plotting of the ln-survivor probability against analysis time revealed that the failure rate for pigs shedding non-hemolytic E. coli was high at first, but rapidly decreased and became constant $(=0)$ after the seventh day after insertion. For these reasons, it was most appropriate to restrictively include observations from the seventh day after the insertion and onwards. Goodnessof-fit tests of the model was performed based on both Pearson and deviance residuals.

\section{Declarations and transparency}

Some of the data included in this publication have been presented in preliminary forms in three master theses submitted to University of Copenhagen in 2020. Oleksandr Kolesnyk and co-author of this paper KTH contributed to the post-mortem exams and some findings were described in their cooperative master thesis. The co-authors MVA and AEC described clinical and microbiological findings in preliminary forms in their master theses. Some of the samples collected during the present work will be analyzed for other purposes presented in separate papers. A Danish resume with preliminary findings have been published previously [80].

\section{Ethics statement}

The principal investigators deemed that the procedures performed would not cause pain, suffering, distress, or lasting harm to an extent where an approval for experimental animal use was necessary according to Danish law [81]. Producer B's own records revealed that some pigs had been weaned when 20 days old. This is not legal practice in Denmark unless due to health or welfare issues (28 days are required, but 21 days of age is permitted when specific requirements to the production system is fulfilled) [82]. In accordance with $\$ 8$ in the Danish veterinary act [83], the veterinarian responsible for the data collection instructed the producer to take actions that would preclude this practice in the future.

\section{Supplementary Information}

The online version contains supplementary material available at https://doi. org/10.1186/s40813-021-00232-z.

Additional file 1. Additional tables with summary of dams and their litters, and primary causes of pre-weaning death.

\section{Acknowledgements}

The authors are very grateful to the herd owners and their herd veterinarians for their great cooperativeness. From SEGES Pig Research Center, we would like to acknowledge the technicians Mogens Jakobsen and Mimi Lykke Mølgaard Eriksen for their contribution to the data and sample collection in the herds as well as senior consultant Julie Krogsdahl Bache for managing and merging datasets. We would like to acknowledge laboratory technician Hue Thi Tranh Tran (University of Copenhagen) for the qPCR rotavirus detection, Oleksandr Kolesnyk for his assistance with the post-mortem exams, and animal caretaker Rasmus Jelle Syhler (University of Copenhagen) for transporting samples and carcasses to the University.

\section{Authors' contributions}

KSP, JPN, NRW, JEO and HEJ conceptualized the study and acquired the funding, KSP, NRW, JPN and EØE designed the study, MVA, AEC, LS, KSP and EØE contributed to the data collections in the herds, EK, AEC MVA, LEL and JEO designed and/or conducted the microbiological laboratory analyses, KTH, KP and HEJ designed and conducted the necropsies and interpret the primary causes of death, EØE and AN designed and performed the statistical analyses, $E \varnothing E, K S P, N R W$, JPN, and JEO interpreted the results, EØE wrote the first manuscript draft. All authors critically revised the manuscript and approved the final version.

\section{Funding}

The work was funded partially by the Danish Veterinary and Food Administration as a part of the research activities funded in Veterinærforlig III (English: Veterinary settlement III) granted to University of Copenhagen, and partially by the Danish Pig Levy Foundation granted to SEGES Danish Pig Research Center. The first author's (EØE) externship at Norwegian University of Life Sciences was the foundation for the collaboration with the co-author ACWN Some expenditures during this stay was sponsored by Norma og Frode Jacobsens Fond.

Availability of data and materials

The data set is available from the first author upon reasonable request.

\section{Declarations}

\section{Competing interests}

The authors affiliated with University of Copenhagen have received funding from the Danish authorities and the pork industry for multiple research projects, including the present. The authors declare that this have not inappropriately influenced the present work.

\section{Author details}

${ }^{1}$ Department of Veterinary and Animal Sciences, University of Copenhagen, Copenhagen, Denmark. ${ }^{2} \varnothing$-Vet A/S, Næstved, Denmark. ${ }^{3}$ SEGES Danish Pig Research Centre, Copenhagen, Denmark. ${ }^{4}$ Department of Production Animal Clinical Sciences, Norwegian University of Life Sciences, Ås, Norway.

Received: 19 July 2021 Accepted: 22 September 2021

Published online: 09 October 2021

References

1. Jensen $P$, Stangel G. Behaviour of piglets during weaning in a seminatural enclosure. Appl Anim Behav Sci. 1992;33(2-3):227-38.

2. Fu ZF, Hampson DJ, Wilks CR. Transfer of maternal antibody against group A rotavirus from sows to piglets and serological responses following natural infection. Res Vet Sci. 1990;48(3):365-73.

3. Poonsuk K, Zimmerman J. Historical and contemporary aspects of maternal immunity in swine. Anim Health Res Rev. 2018;19(1):31-45.

4. Gresse R, Chaucheyras-Durand F, Fleury MA, Van de Wiele T, Forano E, Blanquet-Diot S. Gut microbiota dysbiosis in postweaning piglets: understanding the keys to health. Trends Microbiol. 2017;25(10):851-73.

5. Moeser AJ, Pohl CS, Rajput M. Weaning stress and gastrointestinal barrier development: implications for lifelong gut health in pigs. Anim Nutr. 2017:3(4):313-21.

6. Pluske JR. Invited review: aspects of gastrointestinal tract growth and maturation in the pre- and postweaning period of pigs. J Anim Sci. 2016;94(Suppl. 3):399-411. 
7. Pluske JR, Turpin DL, Kim J-C. Gastrointestinal tract (gut) health in the young pig. Anim Nutr. 2018;4(2):187-96.

8. Campbell JM, Crenshaw JD, Polo J. The biological stress of early weaned piglets. J Anim Sci Biotechnol. 2019. https://doi.org/10.1186/ 2049-1891-4-19.

9. Pluske JR, Miller DW, Sterndale SO, Turpin DL. Associations between gastrointestinal-tract function and the stress response after weaning in pigs. Anim Prod Sci. 2019;59(11):2015-22.

10. van Beers-Schreurs HMG, Vellenga L, Wensing Th, Breukink HJ. The pathogenesis of the post-weaning syndrome in weaned piglets; a review. Vet Q. 1992;14(1):29-34.

11. Luppi A, Gibellini M, Gin T, Vangroenweghe F, Vandenbroucke V, Bauerfeind $R$, et al. Prevalence of virulence factors in enterotoxigenic Escherichia coli isolated from pigs with post-weaning diarrhoea in Europe. Porc Health Manag. 2016;2(1):1-6.

12. Pettersson E, Hestad S, Möttus I, Skiöldebrand E, Wallgren P. Rotavirus and Cystoisospora suis in piglets during the suckling and early post weaning period, in systems with solid floors and age segregated rearing. Porc Health Manag. 2019;5(1):7.

13. Lecce JG, King MW. Role of rotavirus (reo-like) in weanling diarrhea of pigs. J Clin Microbiol. 1978;8(4):5.

14. Lecce JG, Balsbaugh RK, Clare DA. Rotavirus and hemolytic enteropathogenic Escherichia coli in weanling diarrhea of pigs. J Clin Microbiol. 1982;16(4):9.

15. Niederwerder MC, Hesse RA. Swine enteric coronavirus disease: a review of 4 years with porcine epidemic diarrhoea virus and porcine deltacoronavirus in the United States and Canada. Transbound Emerg Dis. 2018;65(3):660-75.

16. Ministry of Environment and Food of Denmark. Animal Health in Denmark 2019. 1st edition. 2020. https://www.foedevarestyrelsen.dk/Publi kationer/Alle\%20publikationer/Animal_Health_in_Denmark_2019.pdf.

17. Page SW, Gautier P. Use of antimicrobial agents in livestock. Rev Sci Tech Int Off Epizoot. 2012;31(1):145-88.

18. Liu Y, Espinosa CD, Abelilla JJ, Casas GA, Lagos LV, Lee SA, et al. Non-antibiotic feed additives in diets for pigs: a review. Anim Nutr. 2018:4(2):113-25.

19. Nielsen CL, Kongsted H, Sørensen JT, Krogh MA. Antibiotic and medical zinc oxide usage in Danish conventional and welfare-label pig herds in 2016-2018. Prev Vet Med. 2021;189:105283.

20. European Commission. Commission Implementing Decision of 26.6.2017 concerning, in the framework of Article 35 of Directive 2001/82/EC of the European Parliament and of the Council, the marketing authorisations for veterinary medicinal products containing "zinc oxide" to be administered orally to food producing species. Annexes I-II-II. Jun 26, 2017. https://ec. europa.eu/health/documents/community-register/2017/2017062613 6754/anx_136754_en.pdf.

21. Marshall $\overline{B M}$, Levy $S B$. Food animals and antimicrobials: impacts on human health. Clin Microbiol Rev. 2011;24(4):718.

22. Scott AM, Beller E, Glasziou P, Clark J, Ranakusuma RW, Byambasuren $\mathrm{O}$, et al. Is antimicrobial administration to food animals a direct threat to human health? A rapid systematic review. Int J Antimicrob Agents. 2018;52(3):316-23.

23. Jensen J, Kyvsgaard NC, Battisti A, Baptiste KE. Environmental and public health related risk of veterinary zinc in pig production—using Denmark as an example. Environ Int. 2018;114:181-90.

24. European Commission. Commission Implementing Decision of 26.6.2017 concerning, in the framework of Article 35 of Directive 2001/82/EC of the European Parliament and of the Council, the marketing authorisations for veterinary medicinal products containing "zinc oxide" to be administered orally to food producing species. Jun 26,2017 . http://ec.europa.eu/ health/documents/community-register/2017/20170626136754/dec_ 136754_en.pdf.

25. The European Parliament and the Council of the Regulation (EC) No 1831/2003 of the European parliament and of the council of 22 September 2003 on additives for use in animal nutrition. Official Journal of the European Union Sep 22, 2003. https://eur-lex.europa.eu/legal-content/ EN/TXT/PDF/?uri=CELEX:32003R1831\&from=en.

26. World Organisation for Animal Health (OIE). OIE Annual report on antimicrobial agents intended for use in animals Fourth Report. World Organisation for Animal Health (OIE); 2020 [cited 2021 Mar 26]. Report No.: 4. https://www.oie.int/fileadmin/Home/eng/Our_scientific_exper tise/docs/pdf/AMR/A_Fourth_Annual_Report_AMR.pdf.
27. Ministry of Environment and Food of Denmark. BEK nr 1227 af 19/11/2019 Bekendtgørelse om dyrlægers anvendelse, udlevering og ordinering af lægemidler til dyr. Nov 19, 2019. https://www.retsinform ation.dk/eli/lta/2019/1227.

28. European Commission. Communication from the commission to the European parliament, the council, the European economic and social committee and the committee of the regions A Farm to Fork Strategy for a fair, healthy and environmentally-friendly food system. May 20, 2020. https://eur-lex.europa.eu/legal-content/EN/TXT/?uri=CELEX: 52020 DC0381.

29. Clark B, Stewart GB, Panzone LA, Kyriazakis I, Frewer LJ. A systematic review of public attitudes, perceptions and behaviours towards production diseases associated with farm animal welfare. J Agric Environ Ethics. 2016;29(3):455-78.

30. Clark B, Panzone LA, Stewart GB, Kyriazakis I, Niemi JK, Latvala T, et al. Consumer attitudes towards production diseases in intensive production systems. PLoS ONE. 2019;14(1):e0210432.

31. Weber NR. Porcine Intestinal Disease Complex in nursery pigs, with special focus on the prudent use of antimicrobials [Ph.D. Thesis]. University of Copenhagen; 2017. https://curis.ku.dk/ws/files/183511479/ Phd_thesis_Nicolai_Weber.pdf.

32. Pedersen KS, Johansen M, Angen $\varnothing$, Jorsal SE, Nielsen JP, Jensen TK, et al. Herd diagnosis of low pathogen diarrhoea in growing pigs-a pilot study. Ir Vet J. 2019. https://doi.org/10.1186/2046-0481-67-24.

33. Chase-Topping ME, Gunn G, Strachan WD, Edwards SA, Smith WJ, Hillman $\mathrm{K}$, et al. Epidemiology of porcine non-specific colitis on Scottish farms. Vet J. 2007;173(2):353-60.

34. Pedersen KS, Okholm E, Johansen M, Angen Ø, Jorsal SE, Nielsen JP, et al. Clinical utility and performance of sock sampling in weaner pig diarrhoea. Prev Vet Med. 2015;120(3-4):313-20.

35. Schulz LL, Tonsor GT. Assessment of the economic impacts of porcine epidemic diarrhea virus in the United States. J Anim Sci. 2015;93(11):5111-8.

36. Cornelison AS, Karriker LA, Williams NH, Haberl BJ, Stalder KJ, Schulz LL, et al. Impact of health challenges on pig growth performance, carcass characteristics, and net returns under commercial conditions. Transl Anim Sci. 2018;2(1):50-61.

37. Rauw WM, Rydhmer L, Kyriazakis I, Øverland M, Gilbert H, Dekkers $J C$, et al. Prospects for sustainability of pig production in relation to climate change and novel feed resources. I Sci Food Agric. 2020;100(9):3575-86.

38. Smith HW, Linggood MA. Observations on the pathogenic properties of the K88, Hly and Ent plasmids of Escherichia Coli with particular reference to porcine diarrhoea. J Med Microbiol. 1971;4(4):467-85.

39. Anneberg I. Hvad fremmer og hvad hindrer landmænd og dyrlæger i at reducere brugen af antibiotika og medicinsk zink til svin? [Internet]. DCA—Nationalt Center for Fødevarer og Jordbrug; 2019. Report No.: 147. https://dcapub.au.dk/djfpublikation/index.asp?action=show\&id= 1290.

40. Winter SE, Winter MG, Xavier MN, Thiennimitr P, Poon V, Keestra AM, et al. Host-derived nitrate boosts growth of $E$. coli in the inflamed gut. Science. 2013;339(6120):708-11.

41. Gilbert MS, lissennagger N, Kies AK, van Mil SWC. Protein fermentation in the gut; implications for intestinal dysfunction in humans, pigs, and poultry. Am J Physiol-Gastrointest Liver Physiol. 2018;315(2):G159-70.

42. García V, Gambino M, Pedersen K, Haugegaard S, Olsen JE, Herrero-Fresno A. F4- and F18-positive enterotoxigenic Escherichia coli isolates from diarrhea of postweaning pigs: genomic characterization. Appl Environ Microbiol. 2020;86(23). https://aem.asm.org/content/86/23/e01913-20.

43. Zajacova ZS, Faldyna M, Kulich P, Kummer V, Maskova J, Alexa P. Experimental infection of gnotobiotic piglets with Escherichia coli strains positive for EAST1 and AIDA. Vet Immunol Immunopathol. 2013;152(1-2):176-82.

44. Dubreuil JD. EAST1 toxin: an enigmatic molecule associated with sporadic episodes of diarrhea in humans and animals. J Microbiol. 2019:57(7):541-9.

45. Melin L, Mattsson S, Katouli M, Wallgren P. Development of post-weaning diarrhoea in piglets. Relation to presence of Escherichia coli strains and rotavirus. J Vet Med Ser B. 2004;51 (1):12-22. 
46. Hampson DJ, Smith WC. Influence of creep feeding and dietary intake after weaning on malabsorption and occurrence of diarrhoea in the newly weaned pig. Res Vet Sci. 1986;41(1):63-9.

47. Feldpausch JA, Jourquin J, Bergstrom JR, Bargen JL, Bokenkroger CD, Davis $\mathrm{DL}$, et al. Birth weight threshold for identifying piglets at risk for preweaning mortality. Transl Anim Sci. 2019;3(2):633-40.

48. Madec F, Bridoux N, Bounaix S, Jestin A. Measurement of digestive disorders in the piglet at weaning and related risk factors. Prev Vet Med. 1998:35(1):53-72.

49. Laine TM, Lyytikäinen T, Yliaho M, Anttila M. Risk factors for post-weaning diarrhoea on piglet producing farms in Finland. Acta Vet Scand. 2008;50(1):21.

50. Rhouma M, Fairbrother JM, Beaudry F, Letellier A. Post weaning diarrhea in pigs: risk factors and non-colistin-based control strategies. Acta Vet Scand. 2017;59(1):31.

51. Dou S, Gadonna-Widehem P, Rome V, Hamoudi D, Rhazi L, Lakhal L, et al. Characterisation of early-life fecal microbiota in susceptible and healthy pigs to post-weaning diarrhoea. PLoS ONE. 2017;12(1):e0169851.

52. Amdi C, Lynegaard JC, Thymann T, Williams AR. Intrauterine growth restriction in piglets alters blood cell counts and impairs cytokine responses in peripheral mononuclear cells 24 days post-partum. Sci Rep. 2020:10(1):1-7.

53. Hales J, Moustsen VA, Nielsen MBF, Hansen CF. Individual physical characteristics of neonatal piglets affect preweaning survival of piglets born in a noncrated system. J Anim Sci. 2013;91(10):4991-5003.

54. Huting AMS, Wellock I, Tuer S, Kyriazakis I. Weaning age and post-weaning nursery feeding regime are important in improving the performance of lightweight pigs. J Anim Sci. 2019;97(12):4834-44.

55. Staarvik T, Framstad T, Heggelund M, Fremgaarden SB, Kielland C. Blood glucose levels in newborn piglets and the associations between bloodglucose levels, intrauterine growth restriction and pre-weaning mortality. Porc Health Manag. 2019;5(1):1-10.

56. Jayaraman B, Nyachoti CM. Husbandry practices and gut health outcomes in weaned piglets: a review. Anim Nutr. 2017;3(3):205-11.

57. Middelkoop A, van Marwijk MA, Kemp B, Bolhuis JE. Pigs like it varied; feeding behavior and pre- and post-weaning performance of piglets exposed to dietary diversity and feed hidden in substrate during lactation. Front Vet Sci. 2019. https://doi.org/10.3389/fvets.2019.00408/full.

58. Huting AMS, Sakkas P, Wellock I, Almond K, Kyriazakis I. Once small always small? To what extent morphometric characteristics and post-weaning starter regime affect pig lifetime growth performance. Porc Health Manag. 2018:4(1):1-14.

59. Kim HB, Isaacson RE. The pig gut microbial diversity: Understanding the pig gut microbial ecology through the next generation high throughput sequencing. Vet Microbiol. 2015;177(3-4):242-51.

60. Eriksen EO, Smed S, Klit KJ, Olsen JE. Factors influencing Danish veterinarians' choice of antimicrobials prescribed for intestinal diseases in weaner pigs. Vet Rec. 2019;184(26):798-798.

61. Østergaard S, Lastein DB, Emanuelson U, Rustas B-O, Krogh MA, Kudahl $A B$, et al. Feasibility of EVolutionary OPeration (EVOP) as a concept for herd-specific management in commercial dairy herds. Livest Sci. 2020;235:104004

62. Fairbrother JM, Nadeau É, Gyles CL. Escherichia coli in postweaning diarrhea in pigs: an update on bacterial types, pathogenesis, and prevention strategies. Anim Health Res Rev. 2005:6(1):17-39.

63. Frydendahl K. Prevalence of serogroups and virulence genes in Escherichia coli associated with postweaning diarrhoea and edema disease in pigs and a comparison of diagnostic approaches. Vet Microbiol. 2002:85(2):169-82.

64. Luppi A. Swine enteric colibacillosis: diagnosis, therapy and antimicrobial resistance. Porc Health Manag. 2017;3(1):16.

65. Weber NR, Nielsen JP, Hjulsager CK, Jorsal SE, Haugegaard S, Hansen CF, et al. Comparison of bacterial culture and GPCR testing of rectal and pen floor samples as diagnostic approaches to detect enterotoxic Escherichia coli in nursery pigs. Prev Vet Med. 2017;143:61-7.

66. O'Connor AM, Sargeant JM, Dohoo IR, Erb HN, Cevallos M, Egger M, et al. Explanation and elaboration document for the STROBE-vet statement: strengthening the reporting of observational studies in epidemiologyveterinary extension. J Vet Intern Med. 2016;30(6):1896-928.

67. Eriksen EØ, Kudirkiene E, Nielsen JP, Olsen JE, Pedersen KS. Post-weaning diarrhea outbreaks in Danish herds not using medicinal zinc oxide. In: Proceedings of the 12th European symposium of porcine health management. The European college of porcine health management Itd.; 2021. p. 75/593.

68. Pedersen KS, Toft N. Intra- and inter-observer agreement when using a descriptive classification scale for clinical assessment of faecal consistency in growing pigs. Prev Vet Med. 2011;98(4):288-91.

69. Kongsted $H$, Jonach B, Haugegaard S, Angen $\varnothing$, Jorsal SE, Kokotovic B, et al. Microbiological, pathological and histological findings in four Danish pig herds affected by a new neonatal diarrhoea syndrome. BMC Vet Res. 2013;9(1):206.

70. Madsen LW, Jensen HE. Necropsy of the pig. In: Jensen HE, editor. Necropsy — a handbook and atlas. 1st ed. Frederiksberg: Biofolia; 2011.

71. Lay JO. MALDI-TOF mass spectrometry of bacteria. Mass Spectrom Rev. 2001;20(4):172-94

72. Zhang W, Zhao M, Ruesch L, Omot A, Francis D. Prevalence of virulence genes in Escherichia coli strains recently isolated from young pigs with diarrhea in the US. Vet Microbiol. 2007;123(1-3):145-52.

73. Goecke NB, Hjulsager CK, Krog JS, Skovgaard K, Larsen LE. Development of a high-throughput real-time PCR system for detection of enzootic pathogens in pigs. J Vet Diagn Investig. 2020;32(1):51-64

74. Pang XL, Lee $B$, Boroumand N, Leblanc B, Preiksaitis JK, Ip CCY. Increased detection of rotavirus using a real time reverse transcription-polymerase chain reaction (RT-PCR) assay in stool specimens from children with diarrhea. J Med Virol. 2004;72(3):496-501.

75. StataCorp. Stata Statistical Software: Release 16. College Station, TX: StataCorp LLC.; 2019.

76. Dohoo IR, Martin W, Stryhn H. Veterinary epidemiologic research [Internet]. 2nd ed. VER Inc.; 2014. 865 p. Available from: Upei.ca/ver

77. Cox DR. Regression models and life-tables. J R Stat Soc Ser B Methodol. 1972:34(2):187-220.

78. O'Quigley J, Xu R, Stare J. Explained randomness in proportional hazards models. Stat Med. 2005:24(3):479-89.

79. Royston P. Explained variation for survival models. Stata J Promot Commun Stat Stata. 2006:6(1):83-96.

80. Skade L, Agerlin MV, Krogsdahl J, Christensen AE, Pedersen KS. MeddeleIse 1217 Smittedynamik og risikofaktorer for E. coli-betinget fravænningsdiarré [Internet]. Seges Danish Pig Research Center; 2021 [cited 2021 Mar 29]. https://svineproduktion.dk/publikationer/kilder/lu_medd/2020/ 1217.

81. Ministry of Environment and Food of Denmark. LBK nr 474 af 15/05/2014 Bekendtgørelse af lov om dyreforsøg. May 20, 2014. https://www.retsi nformation.dk/eli/lta/2014/474.

82. Ministry of Environment and Food of Denmark. BEK nr 17 af 07/01/2016 Bekendtgørelse om beskyttelse af svin. Jan 7, 2016. https://www.retsi nformation.dk/eli/lta/2016/17.

83. Ministry of Environment and Food of Denmark. LBK nr 40 af 15/01/2020 Bekendtgørelse af lov om dyrlæger. Jan 15, 2020. https://www.retsinform ation.dk/eli/lta/2020/40.

\section{Publisher's Note}

Springer Nature remains neutral with regard to jurisdictional claims in published maps and institutional affiliations. 